\title{
Influence of Pavement Condition on Environmental Costs
}

\author{
Luc Pellecuer $^{1}$, Gabriel J. Assaf ${ }^{2}$, and Michèle St-Jacques ${ }^{3}$ \\ ${ }^{1}$ Ph.D. candidate, Département de génie civil, École de Technologie Supérieure, 1100 Notre-Dame Ouest, Montréal, \\ Qc, Canada (corresponding author).E-mail: luc.pellecuer@etsmtl.ca \\ ${ }^{2}$ Professor, Département de génie civil, École de Technologie Supérieure, 1100 Notre-Dame Ouest, Montréal, Qc, \\ Canada. E-mail: gabriel.assaf@etsmtl.ca \\ ${ }^{3}$ Professor, Département de génie civil, École de Technologie Supérieure, 1100 Notre-Dame Ouest, Montréal, Qc, \\ Canada. E-mail: michele.st-jacques@etsmtl.ca
}

\section{Abstract}

Pavement conditions significantly influence the generation of nuisances that influence the environment and induces costs borne by society. This paper presents a new tool designed to monetize and incorporate environmental impacts in decision-making processes. The Pavement Environmental Impact Model (PEIM) is the first attempt to adapt the Impact Pathway Approach (IPA) to assess the emission, dispersion, and impacts of noise, air pollution, and greenhouse gases so that environmental impacts can be included in the economic model of pavement management units. Results of a simulation performed with PEIM for an urban collector road with an annual average daily traffic of 10,000 vehicles per day and a linear density of 240 people per kilometer show that, within the assumptions/limitations of PEIM, environmental costs were expected to range from 876,000 to $1,983,000$ Canadian dollars per kilometer per year for pavement roughness ranging from 1 to $4 \mathrm{~m} / \mathrm{km}$. Moreover, although noise cost is consistently disregarded in pavement management, it was expected to represent $54 \%$ of the total environmental cost when pavement roughness was above $1.75 \mathrm{~m} / \mathrm{km}$. Results demonstrate that PEIM is a suitable tool to roughly estimate environmental costs and to help pavement management units choose the optimal alternative of management.

Subject headings: Pavement management; Environmental issues; Models; Costs; Health hazards 


\section{Introduction}

Road traffic is recognized as a major source of environmental nuisances, such as noise (World Health Organization (WHO) 2011), air pollution (WHO 2013), and greenhouse gases (Environmental Protection Agency 2012). These nuisances significantly and adversely influence the environment in the long term and, consequently, the sustainable development of our society. Because pavement characteristics have a significant influence on the generation of environmental nuisances (Santero and Horvath 2009; Zhang et al. 2010), road agencies are expected to incorporate environmental concerns in their decision-making processes to improve the sustainability of the pavement network.

Over the past two decades, several studies addressing the link between environmental impacts and road traffic have provided techniques and tools to help road agencies account for social and environmental concerns. Two main methods arose from these studies. First, life cycle assessment (LCA), which is not specific to transportation, is a typical method to integrate environmental concerns (Santero et al. 2011). Second, life cycle cost analysis (LCCA), which is widely used by road agencies, represents a suitable framework for integration of sustainability concerns in pavement management (Ozbay et al. 2004). However, most LCA and LCCA applications ignore environmental impacts that occur during the use phase of a pavement's life cycle, such as environmental impacts caused by road traffic, although this is by far the longest phase of a pavement's life cycle (Chan et al. 2008; Gosse et al. 2013; Santero et al. 2011).

Zhang et al. (2013) recently integrated LCA and LCCA into a single tool to establish environmental impacts occurring during the use phase. However, environmental impacts included in their study are limited to global warming and air pollutant effects on human health and the corresponding environmental costs are roughly estimated with respect to the unit damage cost of each pollutant. Based on LCCA and Impact Pathway Approach (IPA) principles, the conceptual model developed by Pellecuer (2014), shows that current knowledge is available from different research fields for integration into a comprehensive practical tool suitable for pavement management units. 
Thus, the purpose of this study is to develop a new tool for assessment of environmental costs. Based on the conceptual model of Pellecuer (2014), this tool assesses the annual environmental impact during the use phase of a pavement's life cycle and estimates the associated costs. This tool, referred to as the Pavement Environmental Impact Model (PEIM), is intended to assess environmental nuisance emission, dispersion, and impacts, and also to assign an economic value to these impacts that can be used in LCCA. The following section presents the model's architecture and describes how pavement characteristics influence environmental impacts related to atmospheric emissions and noise. The model is then evaluated using a sensitivity analysis and the results of a case study. The paper concludes with a discussion of the results and an assessment of the potential and limits of PEIM.

\section{Model description}

\section{Model architecture}

PEIM is designed to appraise the economic value of annual environmental impacts due to traffic on a road section. PEIM integrates current scientific knowledge to estimate environmental nuisance generation and dispersion as well as to quantify and monetize the resulting environmental impacts. A graph of the PEIM architecture including the links between the inputs required to run the model, modules that compose the model, and outputs provided by the model is presented in Fig. 1.

Four types of input are required to run the model: traffic data, climate data, receptor data, and road data. In order to ensure wide suitability to pavement management units, the required data is easily accessible or can be easily estimated. Traffic data comprises annual average daily traffic (AADT), cumulative traffic volume, percentage of heavy vehicles, and average vehicle speed. Receptor data includes the distance from the receptor to the road and the linear population density along the road section. Climate data is limited to average wind velocity and direction. Road data encompasses geometric data typically available at road agencies (length of the road section as well as width and number of traffic lanes) and pavement characteristics that are usually monitored by pavement management units (pavement roughness, texture, 
deflection, and surface age). Distresses such as cracking and potholes are also part of road data and are usually monitored by pavement management units. Such distresses are expected to influence the intensity of environmental nuisances and the resulting environmental impacts. However, they are not considered in PEIM because of the lack of scientific knowledge on the link between the severity of pavement distresses and the intensity of environmental nuisances.

Based partially on the IPA, PEIM consists of four modules describing the impact pathways of noise and atmospheric emissions from the generation and dispersion of these nuisances, and the quantification and valuation of the associated impacts.

The atmospheric emission module computes the fuel consumption of vehicles travelling on the studied road section, the associated amount of chemicals released into the atmosphere, and the concentration of air pollutants at the receptor location.

The noise module computes the noise energy emitted from road traffic and the resulting noise level at the receptor location.

The health module estimates the human health damage from air pollution and noise on receptors with concentration- and exposure-response functions, respectively, which establish the relationship between air pollutant concentration and noise level, and the number and severity of health cases.

The valuation module assigns an economic value to each of the health cases determined by the health module and to each amount of atmospheric emission estimated by the atmospheric emission module that causes environmental impacts other than human health effects (e.g., global warming and building damage). This last economic valuation is performed with exposure-response and exposure-cost functions that describe the relationship between the amount of chemicals released into the atmosphere and the associated environmental impacts and costs.

Given that PEIM aims to compare pavement management alternatives, the assessment of environmental impacts due to controlled intersections, congestion, change in road grade, road alignment, vehicle load 
and condition, and driving style are out of the scope of this study. This implies that both engine and vehicle speeds are assumed to remain constant, and consequently, changes in the generation of environmental nuisances are assumed to be solely due to changes in pavement characteristics and surface conditions. As mentioned above, pavement surface conditions are estimated based on pavement roughness and do not include distresses such as cracking and potholes. Thus, pavement roughness is assumed to adequately represent the pavement condition.

The main output of PEIM is the total annual environmental cost of a road section (in $\left.C A \$_{2000}\right)$. However, detailed environmental costs may be obtained for noise and atmospheric emissions (e.g., noise annoyance costs and global warming costs). In addition, intermediate outputs may be extracted from the noise module (e.g., noise level at the receptor location), the atmospheric emission module (annual amount of $\mathrm{CO}_{2}$ emitted), and the health module (e.g., number of myocardial infarction).

The area of application of PEIM is limited by the assumptions described above and by the uncertainties pertaining to the model and the values of parameters. These limitations and the related impact they have on the model outputs are listed in Table 1.

\section{Atmospheric emissions}

Atmospheric emissions caused mainly by fuel combustion (Bennett and Greenwood 2001) by traffic cause different types of adverse impacts on the environment (e.g., health damages and biodiversity loss). Thus, to assess the environmental impacts of atmospheric emissions, PEIM computes the fuel consumption and estimates the amount of chemicals released into the atmosphere based on the fuel combustion reaction. Then, regarding human health effects, PEIM estimates the concentration of air pollutants at receptors' location, determines the nature and severity of the impacts with concentrationresponse functions that provide the number of the different health cases, and assigns an appropriate economic value to each health case. Regarding effects other than those on human health, an exposure-cost 
function is directly applied to the amount of chemicals released into the atmosphere to estimate the cost of atmospheric emissions.

\section{Fuel consumption and atmospheric emissions}

Fuel consumption is required mainly to overcome traction forces, including rolling resistance that is caused by pavement characteristics. Rolling resistance for vehicle class i on road section $\mathrm{s}\left(F r_{i, s}\right)$ is given by Eqs. (1)-(2) as presented in Bennett and Greenwood (2001) and calibrated by Chatti and Zaabar (2012) for US conditions.

$$
\begin{gathered}
F r_{i, s}=C R 2_{i, s} * \text { FCLIM } *\left(b 11_{i} * N w_{i}+C R 1_{i} *\left(b 12_{i} * M_{i}+b 13_{i} * v_{i, s}^{2}\right)\right) \quad[\mathrm{N}] \\
C R 2_{i, s}=K C r 2_{i} *\left(a 0_{i}+a 1_{i} * T d s p_{s}+a 2_{i} * I R I_{s}+a 3_{i} * D E F_{s}\right)
\end{gathered}
$$

where $C R 2_{i, s}$ is the rolling resistance factor for vehicle class $\mathrm{i}$ on road section s, FCLIM is a climatic factor related to the percentage of driving on snow or wet surfaces, $b 11_{i}$ to $b 13_{i}$ are rolling resistance parameters for vehicle class $\mathrm{i}, N w_{i}$ is the number of wheels for vehicle class $\mathrm{i}, C R 1_{i}$ is the rolling resistance tire factor for vehicle class i, $M_{i}$ is the mass of vehicle class i (tons), $v_{i, s}$ is the vehicle speed on road section s $(\mathrm{m} / \mathrm{s}), K c r 2_{i}$ is the calibration factor for vehicle class $\mathrm{i}, a 0_{i}$ to $a 3_{i}$ are rolling resistance coefficients for vehicle class i, $T d s p_{s}$ is the texture depth of road section s obtained from the sand patch method $(\mathrm{mm}), I R I_{s}$ is the roughness of road section $\mathrm{s}(\mathrm{m} / \mathrm{km})$, and $D E F_{S}$ is the Benkelman Beam rebound deflection of road section $\mathrm{s}(\mathrm{mm})$. For the purpose of this study, it is assumed that the pavement is always dry; therefore, the value of the variable FCLIM is set to 1.

Fuel consumption for vehicle class i on road section $\mathrm{s}\left(\mathrm{FC}_{\mathrm{i}, \mathrm{s}}\right)$ is modeled by the HDM-4 equation that has been calibrated by Chatti and Zaabar (2012) for US conditions:

$$
\mathrm{FC}_{\mathrm{i}, \mathrm{s}}=\frac{10^{3}}{\mathrm{v}_{\mathrm{i}, \mathrm{s}}} *\left(\max \left(\alpha_{\mathrm{i}}, \xi_{\mathrm{i}, \mathrm{s}} *\left(\mathrm{P}_{\mathrm{tr}_{\mathrm{i}, \mathrm{s}}}+\mathrm{P}_{\text {engaccs }_{\mathrm{i}, \mathrm{s}}}\right)\right)\right) \quad[\mathrm{mL} / \mathrm{km}]
$$


where $v_{i, s}$ is the speed of vehicle class $i$ on road section $s(\mathrm{~m} / \mathrm{s}), \alpha_{i}$ is the fuel consumption at idling for vehicle class $\mathrm{i}(\mathrm{mL} / \mathrm{s}), \xi_{\mathrm{i}, \mathrm{s}}$ is the engine efficiency for vehicle class $\mathrm{i}$ on road section $\mathrm{s}(\mathrm{mL} / \mathrm{kW} / \mathrm{s}), \mathrm{P}_{\mathrm{tr}_{\mathrm{i}, \mathrm{s}}}$ is the power required by vehicle class i on road section s to overcome traction forces calculated with Eq. (1) $(\mathrm{kW})$, and $\mathrm{P}_{\text {engaccs }_{i, s}}$ is the power required by vehicle class $\mathrm{i}$ to overcome internal engine friction and to support engine accessories on road section s $(\mathrm{kW})$. Equations providing $\xi_{\mathrm{i}, \mathrm{s}}$ as well as $\mathrm{P}_{\mathrm{tr}_{\mathrm{i}, \mathrm{s}}}$ and $\mathrm{P}_{\text {engaccs }}{ }_{\mathrm{i}, \mathrm{s}}$ are given in Chatti and Zaabar (2012).

Several atmospheric emissions from vehicle fuel combustion adversely impact the environment. Therefore, quantifying these emissions is crucial in assessing their impact on the environment. Estimations of the emission of hydrocarbons (HC), carbon monoxide (CO), nitrogen oxides (NOx), sulfur dioxide $\left(\mathrm{SO}_{2}\right)$, and particulate matter with a diameter of $10 \mu \mathrm{m}$ or less $\left(\mathrm{PM}_{10}\right)$ are based on Eq. (4) and presented in Bennett and Greenwood (2001). Carbon dioxide $\left(\mathrm{CO}_{2}\right)$ emissions are inferred from other emissions by using the chemical equation based on carbon balance presented in Journard et al. (2007). The emission of particulate matter with a diameter of $2.5 \mu \mathrm{m}$ or less $\left(\mathrm{PM}_{2.5}\right)$ is inferred from the $\mathrm{PM}_{10}$ emission, assuming that the ratio $\mathrm{PM}_{2.5} / \mathrm{PM}_{10}$ equals 0.6 (Agence française de sécurité sanitaire environnementale (AFSSE) 2004).

$$
T P E_{i, j, s}=E O E_{i, j, s} * C P F_{i, j} \quad[\mathrm{~g} / \mathrm{km}]
$$

where $T P E_{i, j, s}$ is tailpipe emission of emission $\mathrm{j}$ for vehicle class $\mathrm{i}$ on road section $\mathrm{s}, E O E_{i, j, s}$ is the engine emission of emission j from vehicle class $\mathrm{i}$ on road section $\mathrm{s}(\mathrm{g} / \mathrm{km})$, which is a function of $\mathrm{FC}_{\mathrm{i}, \mathrm{s}}$ and $\mathrm{v}_{\mathrm{i}, \mathrm{s}}$ (see Bennett and Greenwood (2001)), and $C P F_{i, j}$ is the catalyst pass fraction of emission $\mathrm{j}$ from vehicles of class i as defined in Bennett and Greenwood (2001).

For tailpipe emission, the instantaneous emission rate for vehicle tailpipe emission $\mathrm{j}$ on road section $\mathrm{s}$ $\left(E R_{j, s}\right)$ is given by

$$
E R_{j, s}=\frac{1}{8.64 * 10^{10}} * \sum_{i} T P E_{i, j, s} * a_{i} * A A D T_{s} \quad[\mu \mathrm{g} / \mathrm{s} / \mathrm{km}]
$$


where $A A D T_{s}$ is the annual average daily traffic on road section s, $a_{i}$ is the proportion of vehicle class $i$ in the annual average daily traffic, and the factor of $8.64 * 10^{10}$ is a conversion factor (from $\mathrm{g} / \mathrm{day} / \mathrm{km}$ to $\mu \mathrm{g} / \mathrm{s} / \mathrm{km})$.

\section{Atmospheric emissions dispersion}

Because environmental impacts assessed in this study are either local or global, atmospheric emissions are split into two classes: short range emissions encompassing local and regional atmospheric emissions (e.g., particulate matter) and long range emissions (e.g., greenhouse gases). The severity of the impacts due to short range emissions depends on the concentration of the emission at the receptor location, while the severity of the impacts due to long range emissions depends on the global concentration of the gases. Therefore, estimation of emissions dispersion is only required for short range emissions.

Given that road traffic is a continuous linear source, dispersion of short range emissions may be assessed by considering plume dispersion modeling as explained in Hanna et al. (1982). Eq. (6) provides the additional concentration of emission $\mathrm{j}$ due to traffic on road section $\mathrm{s}$ at receptor location $\left(C_{j, s}\left(x^{\text {eff }}\right)\right)$ (Venkatram and Horst 2006).

$$
C_{j, S}\left(x^{e f f}\right)=\sqrt{\frac{2}{\pi}} * \frac{E R_{j, s} * 10^{3}}{U_{S} * \cos \theta_{s} * \sigma_{Z_{S}}\left(x^{e f f}\right)} \quad\left[\mu \mathrm{g} / \mathrm{m}^{3}\right]
$$

where $x^{e f f}$ is the effective downwind distance from the receptor to the road (m). $E R_{j, s}$ is the emission rate of emission $\mathrm{j}$ from road section $\mathrm{s}(\mu \mathrm{g} / \mathrm{s} / \mathrm{km}), U_{s}$ is the average wind velocity on road section $\mathrm{s}(\mathrm{m} / \mathrm{s})$, $\theta_{S}$ is the angle to the normal of road section s at which wind blows, and $\sigma_{Z_{S}}\left(x^{\text {eff }}\right)$ is the vertical dispersion parameter as defined by Hanna et al. (1982):

$$
\sigma_{Z_{S}}\left(x^{e f f}\right)=0.14 *\left(1+0.0003 * x^{e f f}\right)^{-1 / 2} \quad[\mathrm{~m}]
$$




\section{Impacts quantification}

Atmospheric emissions impact human welfare (Kunzli et al. 2000), ecosystems (Bignal et al. 2007), buildings and infrastructure (Rabl and Spadaro 1999), and crops (van Essen et al. 2011). Because the field of human health has attracted major research efforts, the relationship between the level of air pollution and human health is well understood and quantified. Health impacts associated with air pollution encompass the following health outcomes: mortality, respiratory hospital admission, cardiac hospital admission, cardiac emergency visit, restricted activity day, asthma symptom day, acute respiratory symptom day, adult bronchitis case, and child bronchitis case (Feng and Yang 2012; Kunzli et al. 2000; Ostro 1994).

In order to quantify these health impacts, it is necessary to compute the number of annual additional cases due to air pollution. The number of annual additional cases $N_{j, s, h}$ for health outcome h due to trafficinduced atmospheric emissions $\mathrm{j}$ from road section $\mathrm{s}$ is assessed with Eq. (8). This equation is modified from Kunzli et al. (2000).

$$
N_{j, s, h}=C R F_{j, h} * C_{j, s} * N_{h} * P_{s}
$$

where $C R F_{j, h}$ is the concentration-response function, that is, the relative risk for health outcome $\mathrm{h}$ associated with an increase by one unit of the concentration of emission $\mathrm{j}\left(\mu \mathrm{g}^{-1} \cdot \mathrm{m}^{3}\right), N_{h}$ is the base number of cases for health outcome h per person per year, $P_{S}$ is the population exposed to traffic emissions from road section s.

Effects of different emissions may not be fully independent from one another, and therefore, summing up the number of cases due to each emission may lead to double counting in some cases. To avoid overestimation, we chose to calculate the total number of cases for health outcome h due to all trafficinduced atmospheric emissions from road section $s$ as the number of cases due to the most adverse emissions (see Eq. (9)). Thus, this approach is conservative because it may neglect some cases due to less adverse emissions. 


$$
N_{s, h}=\max _{j}\left(N_{j, s, h}\right)
$$

Eqs. (8)-(9) should only be used when emissions feature reliable concentration-response functions. This is the case for $\mathrm{PM}_{10}$ and $\mathrm{PM}_{2.5}$. Other emissions, such as greenhouse gases, sulfur dioxide $\left(\mathrm{SO}_{2}\right)$, and ozone $\left(\mathrm{O}_{3}\right)$, may also significantly impact human health. However, when no impact pathway is available, no reliable concentration-response function is available to quantify the impact of these emissions. The severity of their impact is thus directly measured in economic value, with exposure-cost functions. Additionally, the impact pathway leading to receptors that are not related to human welfare (e.g., deterioration of adjacent buildings and infrastructures as well as ecosystems) are poorly described in literature. Thus, direct exposure-cost functions are used to assess the costs related to these impacts. Finally, atmospheric emissions have detrimental effects on crop production mainly due to ozone (Tong et al. 2007). However, because ozone chemistry is difficult to assess spatially and temporally in the context of pavement management, atmospheric emission impacts on crops are not considered in PEIM.

\section{Impacts monetization}

The economic value associated with impacts of atmospheric emissions due to road traffic $V_{s}$ is calculated using Eq. (10). $V_{S}$ is the sum of the cost associated with health impacts, global warming, biodiversity loss, and building facade soiling and erosion. Health costs include treatment costs, productivity loss costs, and inconvenience costs; global warming costs are those related to damages caused by global warming; biodiversity loss costs are estimated as the damage or restoration costs of the loss; and building damage costs are building facade cleaning and renovation costs.

$$
\begin{gathered}
V_{s}=\sum_{h} U V_{h} * N_{s, h}+U V_{C O_{2} \text { equ }} * 31.536 * E R_{C O_{2} e q u}, s \\
+\sum_{j} U V B L_{j} * L_{j, s}+U V B D_{P M} * 31.536 * E R_{P M, s} * L_{s} \quad\left[\mathrm{CA} \$_{2000}\right]
\end{gathered}
$$


where $U V_{h}$ is the economic value for one case of health outcome $\mathrm{h}\left(\mathrm{CA} \$_{2000} /\right.$ case $), U V_{C O_{2}}$ equ is the economic value of an additional gram of $\mathrm{CO}_{2}$ equ $\left(\mathrm{CA} \$_{2000} / \mathrm{g}\right), E \mathrm{CO}_{2}$ equ, is the emission rate of carbon dioxide $\left(\mathrm{CO}_{2}\right)$ on road section $\mathrm{s}(\mu \mathrm{g} / \mathrm{s} / \mathrm{km}), L_{s}$ is the length of road section $\mathrm{s}(\mathrm{km}), U V B L_{j}$ is the economic value of biodiversity loss due to change in the concentration of emission $\mathrm{j}$ per ton of emission $\mathrm{j}$ $\left(\mathrm{CA} \$_{2000} / \mathrm{ton}\right), U V B D_{P M}$ is the economic value of building damage due to change in the concentration of particulate matter $(\mathrm{PM})$ per ton of $\mathrm{PM}\left(\mathrm{CA} \$_{2000} /\right.$ ton $), E R_{P M, S}$ is the emission rate of PM on road section $\mathrm{s}$ $(\mu \mathrm{g} / \mathrm{s} / \mathrm{km})$, and the factors of 31.536 are conversion factors (from $\mu \mathrm{g} / \mathrm{s} / \mathrm{km}$ to g/year $/ \mathrm{km}$ ).

The economic value associated with health effects corresponds to the sum of treatment costs, which are observed market costs. The economic value associated with carbon dioxide is based on the social cost of carbon, which is an estimate of damages caused by carbon dioxide emissions or, conversely, the benefit of reducing those emissions. This value depends on the climate sensitivity to carbon dioxide concentration, the level of climate damages expected at low temperatures, the level of damages at high temperatures, and the discount rate (Ackerman and Stanton 2012). The economic value associated with biodiversity loss is based on the restoration cost of the ecosystem influenced by the atmospheric emissions from road traffic. The economic value associated with building damage is inferred from the observed cleaning and renovation expenditure.

\section{Noise}

Noise is a major source of environmental impacts in urban areas. According to WHO (1999), noise influences human welfare in both short term (e.g., sleep disturbance) and long term (e.g., cardiovascular diseases) at a degree that depends on the noise level. To assess the nature and severity of noise impacts, PEIM first computes the noise energy emitted by traffic and estimates the noise level at the receptor location. Then, the dose-response functions used by PEIM provide the number of annoyed people and the number of health cases due to the estimated noise level. Finally, the value of noise impacts is estimated by assigning an appropriate economic value to each annoyed person and each health case. 


\section{Emission of sound energy}

The noise module is partly based on the Federal Highway Administration's traffic noise model (TNM). TNM is based on sound energy calculation, for different vehicle classes and different pavement types, in one-third-octave bands (Menge et al. 1998). PEIM is based on version 2.1 of the TNM instead of the subsequent versions because the earlier version has been reported to provide better results than the later versions (Li 2005).

The sound energy associated with a vehicle from vehicle class i travelling on road section s is calculated using

$$
E_{0_{i, s}}=E_{\text {emis,i,upper,ff }}+E_{\text {emis,i,lower,ff }}
$$

where $E_{\text {emis,i,upper,ff }}$ and $E_{\text {emis,i,lower,ff }}$ are the sound energies emitted from the upper and lower subsources of vehicle class i travelling on road section s without intervening ground (Menge et al. 1998).

TNM takes into account the change in noise emission due to a change in pavement type but not to pavement aging. To overcome this shortcoming, Eq. (12) incorporates an adjustment factor developed by Bendtsen et al. (2009). The adjustment factor is calculated as in Eq. (13).

$$
\begin{gathered}
E_{i, s}=E_{0_{i, S}}+10^{\frac{\Delta L_{S}}{10}} \\
\Delta L_{S}=0.25 * \Delta L_{A} * A_{S}+\frac{0.75 * \Delta L_{C T V} * \mathrm{CTV}_{S}}{10^{6} * N_{S}}
\end{gathered}
$$

where $\Delta L_{s}$ is the increase in noise due to pavement aging for road section $\mathrm{s}$, as developed in Bendtsen et al. (2009); $\Delta L_{A}$ is the age component of noise level increase (dBA/year); $A_{s}$ is the age of the pavement (year); $\Delta L_{C T V}$ is the traffic component of noise level increase (dBA/10 $0^{6}$ vehicles); $\mathrm{CTV}_{S}$ is the cumulative traffic volume on road section s; $N_{s}$ is the number of lanes on road section s.

Because noise level variations during a day may impact the calculation of the noise level indicator, the total sound energy from overall traffic on road section $\mathrm{s}$ is first calculated for the $\mathrm{k}^{\text {th }}$ hour of the day using 


$$
T E_{s, k}=\sum_{i} 0.0476 * E_{i, s} * \frac{a_{i} * b_{k^{*}} A A D T_{S}}{v_{i}}
$$

where $b_{k}$ is the proportion of the annual average daily traffic for the $\mathrm{k}^{\text {th }}$ hour of the day. The factor of 0.0476 takes into account the relationship between the maximum instantaneous sound energy for a single vehicle and the time-average sound energy for a stream of traffic, as explained in Menge et al. (1998).

The noise level at the source for the $\mathrm{k}^{\text {th }}$ hour of the day on road section $\mathrm{s}$ is then estimated for a hypothetical location $15 \mathrm{~m}$ from the road, without any influence of intervening ground, using

$$
L_{0_{s, k}}=10 * \log \left(T E_{s, k}\right) \quad[\mathrm{dBA}]
$$

\section{Propagation of traffic noise}

Assuming that no object interferes with sound propagation, sound energy declines with increase in the distance between receptor and emitter, as it is attenuated by absorption by the atmosphere and ground. Eq. (16) adjusts the noise level provided by Eq. (15) to take into account the distance between dwellings and the road as well as the ground characteristics.

$$
L_{s, k}(x)=L_{0_{s, k}}+10 * \log \left(\frac{15}{x}\right)^{1+\propto} \quad[\mathrm{dBA}]
$$

where $x$ is the distance from the receptor to the centerline of the road (m), and $\propto$ is a ground absorption effect parameter. In Eq. (16), the receptor is assumed to be close enough to the road so that the road section length appears as infinite from the receptor position (i.e., $x \ll L_{S}$ ).

\section{Impacts quantification}

Traffic noise only influences ecosystems and human welfare. However, because of the lack of studies on the impact of noise on ecosystems, this study limits noise impacts to those influencing human welfare. Impacts of traffic noise on human welfare are twofold: health effects and annoyance. 
According to Staatsen et al. (2004) and Davies and Kamp (2012), traffic noise significantly influences the following main health outcomes: myocardial infarction (which may lead to early death, days in hospital, days absent from work, and cases of morbidity), angina pectoris (which may lead to days in hospital, days absent from work, and days of morbidity), and hypertension (which may lead to days in hospital). Because the $\mathrm{L}_{\mathrm{den}}$ noise level is commonly used in health impact assessment of noise, the quantification of the severity of traffic noise impact on the above health outcomes is based on $\mathrm{L}_{\mathrm{den}}$. $\mathrm{L}_{\mathrm{den}}$ is a noise indicator computed as an average of the noise emitted during three different periods (day, evening, and night), with penalties for evening and night periods. Distinguishing these periods allows for consideration of the difference in sensitivity to noise during each of the periods (see Eq. 17). Then, the number of cases for each health outcome h occurring along road section $\mathrm{s}\left(N_{s, h}\right)$ is calculated from $\mathrm{L}_{\mathrm{den}}$ using Eq. (18).

$$
\begin{gathered}
L_{d e n_{s}}(x)=10 * \log \left(\frac{\sum_{k=1}^{24}\left(10^{\left.\frac{L_{S, k}(x)+P_{d e n_{k}}}{10}\right)}\right.}{24}\right) \\
N_{s, h}=a_{h} *\left(L_{d e n_{s}}-b_{h}\right) * \frac{P_{S}}{1000}
\end{gathered}
$$

where $P_{\text {den }_{k}}$ is the penalty for the $\mathrm{k}^{\text {th }}$ hour of the day; $a_{h}$ and $b_{h}$ are parameters taken from Staatsen et al. (2004), for each health outcome $\mathrm{h}$; and $P_{S}$ is the population exposed to traffic noise from road section s.

Annoyance severity related to traffic noise is usually expressed as the percentage of people lightly annoyed, annoyed, and highly annoyed (Miedema and Oudshoorn 2001). These percentages are assessed using

$$
X A_{s}=a_{X A} *\left(L_{d e n_{s}}-L_{X A}\right)^{3}+b_{X A} *\left(L_{d e n_{s}}-L_{X A}\right)^{2}+c_{X A} *\left(L_{d e n_{s}}-L_{X A}\right) \quad[\%]
$$

where $X A_{s}$ is alternatively the percentage of lightly annoyed, annoyed, and highly annoyed people because of traffic noise; $a_{X A}, b_{X A}, c_{X A}$, and $L_{X A}$ are parameters taken from Miedema and Oudshoorn (2001). 


\section{Impacts monetization}

Monetization of health effects and annoyance due to traffic noise is performed using

$$
V_{S}=\sum_{h} U V_{h} * N_{S, h}+\delta * \sum_{X A} U V A_{X A} * X A_{S} \quad\left[\mathrm{CA} \$_{2000}\right]
$$

where $U V_{h}$ is the economic value for one case of health outcome $\mathrm{h}\left(\mathrm{CA} \$_{2000} /\right.$ case $) ; U V A_{X A}$ is the economic value for one person alternatively lightly annoyed, annoyed, and highly annoyed per year (CA $\$_{2000} /$ year); and $\delta$ is a coefficient equal to 0 when $L_{d e n_{s}}$ is superior to $70 \mathrm{dBA}$ and to 1 otherwise, and which is applied in order to avoid the double counting of costs related to annoyance.

The economic value associated with health effects corresponds to the sum of treatment costs, which are observed market costs. The economic values associated with annoyance are estimated based on stated preference methods, because these three impacts are not closely related to real market costs. Stated preference methods rely on surveys from which investigators infer willingness to pay and willingness to accept compensation (i.e., how much people would pay or what payment people would expect to receive, in order to avoid or accept a particular impact, respectively). A detailed presentation of these methods is found in Pearce et al. (2006).

\section{Simulation scenario}

PEIM was applied to a hypothetical $1 \mathrm{~km}$ long collector road section located in a densely populated residential urban area of the province of Quebec, Canada. Parameterization of PEIM was performed to adapt the four constituting modules to the context of Quebec. However, regarding vehicle fleet characteristics (e.g., vehicle technology), relative risk estimation (e.g., cardiovascular risk), and costs related to some environmental impacts (e.g., cost of one ton of $\mathrm{CO}_{2}$ ), parameter values were taken directly from literature. The parameters values are described in Table 2. 
On the contrary, in order to be representative of an urban collector road, traffic characteristics, namely, annual average daily traffic, vehicle speed, and percentage of heavy vehicles, were set to 10,000 vehicles, $50 \mathrm{~km} / \mathrm{h}$, and $5 \%$, respectively.

Regarding variables describing pavement characteristics, pavement texture depth obtained from the sand patch method was set to the average value of $1.15 \mathrm{~mm}$ as measured by the Quebec Ministry of Transportation (MTQ, personal communication, 2013), and the Benkelman Beam rebound deflection was assumed to be equal to 0 because the collector featured a low percentage of heavy vehicles. For a given pavement structure, functional class, and traffic level, the relationship between pavement age and International Roughness index (IRI) can be estimated with deterioration models from MTQ (personal communication, 2013). For our simulation scenario, that is, an urban collector road carrying an AADT of more than 4000 vehicles and paved with a new dense-graded asphalt concrete, IRI is estimated using

$$
I R I=1+0.15 * \text { age } \quad[\mathrm{m} / \mathrm{km}]
$$

Climatic and receptor characteristics followed these assumptions: the average wind direction was normal to the road and the average wind velocity was equal to $1 \mathrm{~m} / \mathrm{s}$; because the road section was in a densely populated area, the linear population density was established at 240 people $/ \mathrm{km}$, and the distance between the facade of houses and the road was set to $5 \mathrm{~m}$.

\section{Results}

\section{Sensitivity analysis}

The severity and costs of environmental impacts caused by pavement management are influenced by parameters on which pavement management units have no control. Most of these parameters may be classified into two main classes: one class related to traffic (i.e., traffic volume, vehicle speed, and percentage of heavy vehicles) and another related to receptors (i.e., distance from the receptors to the road 
and density of receptors). The value of these parameters varies with time, is influenced by uncertainty, and requires a sensitivity analysis to be performed on the influential traffic and receptor parameters.

\section{Sensitivity of environmental nuisance indicators}

Equivalent noise level as well as pollutant and greenhouse gas emissions are widely used indicators of assessment midpoint in impact assessment studies related to environmental noise level, air quality, and global warming (Ackerman and Stanton 2012; Cucurachi et al. 2012; Kunzli et al. 2000). In order to use comparable indicators, the amount of emitted $\mathrm{PM}_{2.5}, \mathrm{~L}_{\mathrm{den}}$, and the amount of emitted $\mathrm{CO}_{2}$ were used to assess the environmental nuisances simulated by PEIM.

Sensitivity analysis was performed by changing the value of the vehicle speed, traffic volume, percentage of heavy vehicles, and distance from receptor to road, one at a time while keeping all other parameters at their base values. Fig. 2 presents the change in percent of $\mathrm{L}_{\mathrm{den}}, \mathrm{PM}_{2.5}$, and $\mathrm{CO}_{2}$ emissions relative to their base values. Sensitivity to the density of receptors is not included in Fig. 2 because this parameter is not involved in the calculation of these outputs.

On first sight, irrespective of the parameter under consideration, the responses of $\mathrm{L}_{\mathrm{den}}, \mathrm{PM}_{2.5}$, and $\mathrm{CO}_{2}$ showed dissimilar behaviors. This was because they depend on radically different processes. $\mathrm{L}_{\mathrm{den}}$ depends on noise emission at pavement-tire interface, which is a mechanical process, whereas $\mathrm{PM}_{2.5}$ and $\mathrm{CO}_{2}$ emissions depend on fuel consumption, which involves both mechanical and chemical processes.

Three conclusions may be drawn from the sensitivity analysis to vehicle speed. First, vehicle speed influenced $\mathrm{L}_{\mathrm{den}}$ almost linearly: the higher the vehicle speed, the higher was $\mathrm{L}_{\mathrm{den}}$ (Fig. 2(a)). Because $\mathrm{L}_{\mathrm{den}}$ is a combination of traffic noise levels at each hour of the day, the pseudo-linearity of the curve was consistent with the relationship between the instantaneous vehicle speed and the instantaneous vehicle noise level under cruising conditions as illustrated in Menge et al. (1998). At high speed, the increased friction at the pavement-tire interface induces vibrations that in turn cause noise. Consequently, as depicted in Fig. 2(a), noise level increases with vehicle speed. Second, vehicle speed notably influenced 
$\mathrm{PM}_{2.5}$ and $\mathrm{CO}_{2}$ emissions. Minimum emissions of $\mathrm{PM}_{2.5}$ and $\mathrm{CO}_{2}$ were obtained for speeds equal to about $45 \mathrm{~km} / \mathrm{h}$ and $60 \mathrm{~km} / \mathrm{h}$, respectively. At first glance, the curves may appear counterintuitive, especially at low speeds because $\mathrm{PM}_{2.5}$ and $\mathrm{CO}_{2}$ emissions from one vehicle are commonly considered to be lower when speed decreases. However, the indicators presented here are the amounts of $\mathrm{PM}_{2.5}$ and $\mathrm{CO}_{2}$ emitted along the road section, and at low speeds, vehicles spend more time on the studied road section, consequently emitting more $\mathrm{PM}_{2.5}$ and $\mathrm{CO}_{2}$ while travelling on the road section. Third, at low speeds, $\mathrm{CO}_{2}$ was the most influenced indicator, whereas at high speeds, $\mathrm{PM}_{2.5}$ was the most influenced. Conversely, $\mathrm{L}_{\mathrm{den}}$ was never greatly influenced by vehicle speed. These observations imply that the atmospheric emission module was influenced more significantly than the noise module by vehicle speed, especially at low speeds. These observations also imply that for vehicle speeds out of the range $40-60 \mathrm{~km} / \mathrm{h}$, the vehicle speed value should be carefully estimated.

Traffic volume had a limited effect on $\mathrm{L}_{\text {den }}$; an increase in traffic volume from 2000 to 25,000 vehicles induced an increase of only about $20 \%$ in $\mathrm{L}_{\mathrm{den}}$ and this effect tended to decrease as traffic volume increased. This phenomenon, depicted on the graph by the concavity of the curve (Fig. 2(b)), is consistent with the calculation method of $\mathrm{L}_{\mathrm{den}}$ that involves the logarithm of traffic volume. Although its effect on $\mathrm{L}_{\text {den }}$ was limited, traffic volume greatly influences $\mathrm{PM}_{2.5}$ and $\mathrm{CO}_{2}$ emissions. Fig. 2(b) suggests a proportional relationship between traffic volume and $\mathrm{PM}_{2.5}$ and $\mathrm{CO}_{2}$ emissions. Because these emissions are correlated to total fuel consumption on the road section, this observation is consistent with the fact that an increase in the number of vehicles that travel on the road section induces the same level of increase in fuel consumption. Overall, the atmospheric emission module was notably more influenced than the noise module by traffic volume. Consequently, the value of the traffic volume in the model should be carefully estimated to obtain reliable $\mathrm{PM}_{2.5}$ and $\mathrm{CO}_{2}$ response values. However, if noise is the only output under consideration, a meticulous appraisal of the traffic volume is only needed for relatively low values of traffic volume. 
The percentage of heavy vehicles $(\% \mathrm{HV})$ influenced $\mathrm{L}_{\text {den }}$ positively, and the relationship between $\% \mathrm{HV}$ and $L_{\text {den }}$ was almost linear. This response was expected because heavy vehicles emit more noise than lighter ones (Fig. 2(c)). The percentage of heavy vehicles had similar effects on $\mathrm{PM}_{2.5}$ and $\mathrm{CO}_{2}$ emissions: the relationship between $\% \mathrm{HV}$ and $\mathrm{PM}_{2.5}$ and $\mathrm{CO}_{2}$ emissions was linear. However, the magnitude of the effect was higher for $\mathrm{PM}_{2.5}$ emissions than for $\mathrm{L}_{\mathrm{den}}$ and $\mathrm{CO}_{2}$ emissions. This is because heavy vehicles are a lot more susceptible to emitting PM than lighter ones, whereas the difference regarding $\mathrm{CO}_{2}$ emissions is far less marked (see coefficient values for different types of emissions in Bennett and Greenwood (2001)).Particular caution should be observed for any \%HV value because a slight change in value has a significant influence on $\mathrm{L}_{\mathrm{den}}, \mathrm{CO}_{2}$, and especially $\mathrm{PM}_{2.5}$.

The distance from receptor to road $\left(\mathrm{D}_{\mathrm{RR}}\right)$ had no influence on the amount of $\mathrm{PM}_{2.5}$ and $\mathrm{CO}_{2}$ emissions because this distance is not involved in the generation processes of atmospheric emissions. However, $D_{R R}$ had a significant influence on $\mathrm{L}_{\mathrm{den}}$ (Fig. 2(d)). Because of the attenuation of sound energy by the atmosphere, the noise level decreases with increasing the distance of the facade of houses from the road. The curve convexity observed in Fig. 2(d) is from the calculation method of $\mathrm{L}_{\mathrm{den}}$ that involves the logarithm of $D_{R R}$. Consequently, the $D_{R R}$ value that is input into the model should be carefully estimated in the case of low $D_{R R}$ values, that is, in the case of receptors close to the road because it implies a significant change in $\mathrm{L}_{\mathrm{den}}$. Conversely, because the influence on $\mathrm{L}_{\mathrm{den}}$ is minimal for high $\mathrm{D}_{\mathrm{RR}}$ values, the estimation of $D_{R R}$ does not need to be accurate.

\section{Sensitivity of health indicators}

Environmental nuisances such as noise and air pollution can result in health effects such as mortality and chronic or acute diseases. These health effects are often referred to as assessment endpoints in impact assessment studies (Cucurachi et al. 2012; Kunzli et al. 2000). Thus, the percentage of the population that is annoyed by noise and the number of hospital admissions caused by air pollution were used to assess the health effects simulated by PEIM. With respect to the health indicator for noise impacts, the percentage of 
population annoyed by noise was preferred to the number of days in hospital caused by noise (which is also an output of the model), because hospital admissions due to noise only occur when noise levels are high (above $70 \mathrm{dBA})$.

Sensitivity analysis was performed by changing the value of the vehicle speed, traffic volume, percentage of heavy vehicles, and distance from receptor to road, one at a time while keeping all other parameters at their base values. Fig. 3 presents the change in percent of the population annoyed by noise and of the hospital admissions due to air pollution relative to their base values. Sensitivity to the density of receptors is not included in Fig. 3 because this parameter clearly does not influence the percentage of the population annoyed by noise and does clearly influences the number of hospital admissions in a proportional manner.

Because noise annoyance and hospital admissions caused by air pollution are closely linked to $\mathrm{L}_{\mathrm{den}}$ and $\mathrm{PM}_{2.5}$ respectively, it is not surprising that PEIM behavior was almost identical during the sensitivity analyses of environmental nuisance indicators and health indicators. Consequently, the conclusions drawn from the sensitivity analysis of environmental nuisance indicators remain valid for the sensitivity analysis of health indicators.

However, two further important observations can be made. First, Fig. 3 illustrates that noise annoyance is influenced significantly more by each of the four parameters than by $\mathrm{L}_{\mathrm{den}}$ : sensitivity to vehicle speed (Fig. 3(a)) was four times higher for noise annoyance than for $L_{\text {den }}$ (Fig. 2(a)), while sensitivities to traffic volume (Fig. 3(b)), \%HV (Fig. 3(c)), and $\mathrm{D}_{\mathrm{RR}}$ (Fig. 3(d)) were at least six, five, and three time higher, respectively. This implies that noise $L_{\text {den }}$ was a less accurate indicator of noise impact than noise annoyance and that careful noise annoyance parameterization is all the more important in order to obtain reliable health outputs related to noise. Second, although $\mathrm{D}_{\mathrm{RR}}$ did not influence the amount of $\mathrm{PM}_{2.5}$ emitted by road traffic (Fig. 2(d)), it did influence hospital admissions due to air pollution (Fig. 3(d)). This observation is consistent with the fact that the farther the receptor is from the road, the lesser the $\mathrm{PM}_{2.5}$ concentration is, and the convexity of the curve is because of the pollutant dispersion process. 
Therefore, especially at low $D_{R R}$ values, the $D_{R R}$ value that is input into the model should be carefully estimated.

\section{Environmental costs}

Assigning an economic value to environmental impacts is an effective way to incorporate them in pavement management systems along with agency and user costs. PEIM has the ability to provide annual environmental costs related to the main impacts of noise, greenhouse gases, and air pollution. To illustrate the potential of PEIM, simulations were performed for an urban collector road section located in a densely populated area and paved with a dense-graded asphalt concrete. Values of all inputs, including traffic volume, were assumed to remain stable over years, with the exception of pavement roughness that changed according to pavement age (see Table 13). Because the AADT of the studied road was more than 4,000 vehicles and paved with a new dense-graded asphalt concrete, change in pavement roughness was computed using Eq. (21). Fig. 4 presents the variations in environmental costs with the age of the pavement surface. The horizontal axis represents pavement surface age ranging from 5 to 20 years but may also be interpreted as the pavement roughness because a linear relationship between pavement age and roughness was assumed (see Table 13) based on the data from MTQ (personal communication, 2013).

Fig. 4 shows the annual air pollution, global warming, and noise costs at different ages of the pavement that added to the costs occurring during the first year of the pavement. Additional costs were similar for air pollution (from 8,000 to 33,000 Canadian dollars, Fig. 4(a)) and global warming (from 5,000 to 20,000 Canadian dollars, Fig. 4(b)), whereas additional noise cost was one order of magnitude higher (from 950,000 to 1,053,000 Canadian dollars, Fig. 4(c)). This difference in order of magnitude reveals that noise cost may be significantly more than other environmental costs when pavements get older. This was confirmed by the annual increase rates that were around 1,600 and 1,000 Canadian dollars per year for air pollution and global warming respectively, while this rate was around 6,800 Canadian dollars per 
year for noise (except at the age of 5 because of a threshold effect; see explanation below). Furthermore, the annual increase rate of the global warming cost remained constant, the annual increase rate of air pollution cost increased slightly, and the annual increase rate of noise cost significantly increased. These changes in the annual increase rate indicate an acceleration of the increase of environmental costs related to air pollution and noise, whereas global warming costs increased linearly with pavement age. Therefore, pavement surface age (or condition) influences variations in air pollution and noise costs more than variations in global warming costs.

The annual total cost of environmental impacts is presented in Fig. 5 for different ages of the pavement surface. Remarkably, the total environmental cost more than doubled between year 0 (876,000 Canadian dollars) and year 5 (1,840,000 Canadian dollars) and then continued to increase slightly with a value of 1,983,000 Canadian dollars in year 20. The noticeable increase in year 5 is mainly due to the sudden increase in noise cost caused by an $\mathrm{L}_{\mathrm{den}}$ threshold (at $70 \mathrm{dBA}$ ) beyond which a certain percentage of people need to be admitted to hospital. This phenomenon is also noticeable in Fig. 4(c) where there is a very high value of the annual increase rate of noise cost in year 5. Beyond year 5, noise, global warming, and air pollution costs had the same order of magnitude: noise cost represented about $54 \%$ of the total environmental cost, global warming about $19 \%$, and air pollution about $27 \%$. The preeminence of noise costs has to be stressed here because noise costs are consistently omitted in pavement management studies.

Errors bars shown on Fig. 5 illustrate the uncertainty pertaining to quantification and monetization of health effects as well as to monetization of global warming impacts. These error bars were calculated with the lowest and highest estimates of parameters involved in the quantification and valuation processes for each nuisance impact. Therefore, they represent the low and high estimates of the total annual cost. These error bars do not incorporate the uncertainty regarding the monetization of noise annoyance because of the lack of sensitivity analysis regarding this process in literature. The error bars show that the high and low estimates of the environmental cost remained at the same order of magnitude as the central estimate. 
In year 5 and after, that is, after the $\mathrm{L}_{\mathrm{den}}$ threshold is exceeded, high estimates were less than the double of central estimates (166\%), whereas low estimates were more than half $(60 \%)$. The estimated ranges depicted by the error bars resulted mainly from the difference between low and high estimates of air pollution costs. This difference was responsible for the difference of one order of magnitude between the low and central estimates of the total annual cost in year 0 , that is, when the $\mathrm{L}_{\mathrm{den}}$ threshold was not exceeded and noise cost was minimal.

\section{Discussion}

PEIM has limitations that should be kept in mind when analyzing the results presented above (see Table 1). These limitations are of two kinds. First, the lack of knowledge prevents PEIM from addressing all type of pavement distresses and all types of impacts on all types of receptors. Environmental impacts and costs computed by PEIM are thus expected to be minimized. Second, the hypotheses underlying PEIM restrict its use to simple case studies (i.e. continuous traffic, constant speed, straight road) and assume that environmental impacts caused by a certain level of nuisance and the related costs are the same in North America and Europe. Moreover, the hypothesis that noise causes severe health effects such as early deaths and hospital admissions has not been validated yet even if it is deemed highly plausible (Davies and Kamp 2012; Staatsen et al. 2004). These limitations are reflected in the uncertainties affecting the outputs of PEIM as explained below.

Assigning an economic value to road traffic impacts on the environment is recognized to imply unavoidable uncertainties (Bickel et al. 2006; van Essen et al. 2011). PEIM is no exception and provides results that are subject to uncertainties that pertain to variable estimation, model parameterization, and gaps in scientific knowledge (see Table 1). First, regarding variable estimation, sensitivity analyses show that the change in the value of vehicle speeds, traffic volume, percentage of heavy vehicles, and distance from receptor to road may significantly influence model outputs. Moreover, assuming that Benkelman Beam rebound deflection is equal to zero or that the relationship between pavement roughness and age is 
linear, also introduces uncertainty in model outputs. Therefore, the uncertainty associated with definitions and estimation of variables is clearly reflected in the model outputs.

Second, assumptions concerning the parameters involved in the four modules are also sources of uncertainty. On one hand, parameters related to nuisance generation and dispersion modules are generally well documented and the associated uncertainty remains marginal. On the other hand, quantification and monetization of environmental effects imply uncertainties because of lack of scientific knowledge, e.g., knowledge on magnitude of climate change impacts, on economic valuation of biodiversity loss, or even on the existence of a threshold effect in health effects caused by noise.

Third, another source of uncertainty lies in gaps in scientific knowledge that influence impact pathways. For instance, it remains impossible to incorporate impacts related to vibration or impacts of air pollution on crops in a reliable manner. Furthermore, some impact pathways are still incomplete and use conservative aggregated exposure-cost functions instead of detailed impact pathways (e.g., biodiversity losses due to air pollution). Because PEIM does not assess a few environmental impacts and considers others in a conservative manner, the environmental costs assessed with PEIM are expected to be consistently minimal. Uncertainty due to gaps in scientific knowledge may thus influence the total environmental cost, but it can be reasonably assumed that the biggest share of total environmental cost pertains to impacts that are already well understood and documented.

Finally, it is important to stress that the three kinds of uncertainties described above are not inherent to the methodology and can be reduced by careful data collection and further research. In particular, future research should confirm which pavement characteristics influence the most environmental nuisances. Except for atmospheric emissions that are already well documented, mechanisms of nuisance generation should then be further investigated in order to develop mechanistic model linking the emission of nuisances to pavement characteristics. Future research should also address the lack of knowledge regarding quantification of health effects. This implies further epidemiological studies validating the assumption that noise causes severe health effects and refining concentration-response functions. 
Additionally, the economic value of the environmental impacts that have no market value, such as noise annoyance and loss of biodiversity, should be confirmed by further studies.

Because of the uncertainties discussed above, which are in part illustrated by the error bars in Fig. 5, PEIM outputs are currently limited to rough estimates of environmental costs. However, despite these uncertainties, PEIM provides an opportunity to quantify the influence of pavement age or condition on environmental costs and to provide an order of magnitude of environmental costs, which are essential in comparing the performances of pavement management alternatives.

To our knowledge, this study is the first to assign economic values to this influence, and no environmental costs related to changes in pavement age and condition are documented in literature. Bickel et al. (2006) and Weisbrod et al. (2009) proposed marginal economic values for annual environmental costs due to road traffic resulting from the aggregation of data that were averaged over all classes of roads and all classes of population density and thus represented average estimates. Applying their values in the scenario defined for previous simulations resulted in the cost of environmental impacts ranging from 108,000 to 327,000 Canadian dollars. Given the uncertainties present in quantification and economic valuation of environmental impacts, and given that the environmental costs inferred from literature and those provided by PEIM remained at the same order of magnitude, the difference in their estimates seems reasonable. Moreover, this difference is all the more reasonable than the PEIM simulations that provided expectable higher estimates of environmental costs because the simulation results obtained with PEIM corresponded to a specific case of an urban collector road in a densely populated area, implying that more people were impacted by road traffic nuisances. Thus, PEIM is considered to properly estimate the magnitude of environmental costs associated with pavement age or condition.

More particularly, PEIM may be considered suitable to compare alternatives of management or to justify maintenance and rehabilitation actions. Taking the simulation performed above as an example, Fig. 5 shows that the total environmental cost increased by around 9,000 Canadian dollars per year, yielding a 
total environmental cost of 75,000 Canadian dollars after 8 years, that is, a cost of 75,000 Canadian dollars for a pavement roughness increase of $1.2 \mathrm{~m} / \mathrm{km}$. According to MTQ (personal communication, 2013), preventive maintenance techniques provide a pavement roughness improvement of $1.2 \mathrm{~m} / \mathrm{km}$ at a cost between 40,000 and 100,000 Canadian dollars for the simulated road section. Comparing the maintenance technique costs and the total environmental cost calculated by PEIM, it can be concluded that such a preventive maintenance action may be justified by the environmental cost alone. This brief example shows that, despite uncertainties, PEIM can help pavement management units quantify the magnitude of environmental impacts in relation to their decisions.

\section{Conclusions}

Road conditions contribute significantly adverse impacts on the environment. Methods and tools have been developed over the last two decades in pursuit of sustainability to assess environmental impacts. However, none of these methods and tools allow appropriate economic valuation of these impacts for incorporation in pavement management systems. PEIM presented in this paper is a novel approach based on IPA principles to incorporate environmental impacts due to pavement conditions in pavement management. Based on four modules describing generation, dispersion, impact quantification, and monetization of noise and atmospheric emissions, the model provides costs associated with biodiversity losses, productivity losses, building damages, and health effects that may be input in LCCA tools.

Results of the sensitivity analysis show that PEIM is reliable. These results also underline the importance of careful data collection in order to obtain reasonable output values. Additionally, a simulation for an urban collector road in a densely populated area shows that, within the limitations of the model, environmental costs were expected to range from 876,000 to $1,983,000$ Canadian dollars per kilometer for a pavement age ranging from 0 to 20 years (or pavement roughness ranging from 1 to $4 \mathrm{~m} / \mathrm{km}$ ). Moreover, even if noise cost is never taken into account in pavement management, it was expected, within the assumptions of the model, to represent $54 \%$ of the total environmental impact after year 5 (or 
pavement roughness beyond $1.75 \mathrm{~m} / \mathrm{km}$ ). Finally, PEIM is shown to be the most comprehensive tool that can assist pavement management units in the assessment of the environmental impacts. However, environmental costs from PEIM should be considered with care as they may represent a low estimate of the total environmental cost as it only provides an order of magnitude of this cost. Further research is needed to overcome the uncertainties due to lack of scientific knowledge and to get more accurate estimates of environmental costs. In particular, quantification and monetization of health effects should be considered as a priority for future research.

In summary, PEIM is a comprehensive tool that offers pavement management units new possibilities in their decision-making processes to achieve sustainability. By assessing and incorporating environmental nuisances caused by road traffic, PEIM provides an opportunity to compute costs of various types of environmental impacts related to pavement conditions.

\section{Acknowledgements}

We would like to thank the MTQ (ministère des Transports du Québec) for their collaboration in providing some of the data used in this study. We would also like to sincerely thank Yves Savard and Martin Boucher for their valuable help and support, and three anonymous reviewers for their very helpful comments on the manuscript. This study was supported in part by a fellowship from the FQRNT (Fonds québécois de la recherche sur la nature et les technologies). 


\section{References}

Ackerman, F., and Stanton, E. A. (2012). "Climate risks and carbon prices: Revising the social cost of carbon." Economics, 6.

AFSSE (2004). "Impact sanitaire de la pollution atmosphérique urbaine: Rapport 1." Agence française de sécurité sanitaire environnementale.

Bendtsen, H., Lu, Q., and Kohler, E. (2009). "Acoustic Aging of Asphalt Pavements: A Californian/Danish Comparison." California Department of Transportation, 98.

Bennett, C. R., and Greenwood, I. D. (2001). Modelling road user and environmental effects in HDM-4.

Bickel, P., Friedrich, R., Link, H., Stewart, L., and Nash, C. (2006). "Introducing environmental externalities into transport pricing: Measurement and implications." Transport Reviews, 26(4), 389-415.

Bignal, K. L., Ashmore, M. R., Headley, A. D., Stewart, K., and Weigert, K. (2007). "Ecological impacts of air pollution from road transport on local vegetation." Applied Geochemistry, 22(6), 1265-1271.

Bouchard, M., and Smargiassi, A. (2008). "Estimation des impacts sanitaires de la pollution atmosphérique au Québec : essai d'utilisation du Air Quality Benefits Assessment Tool (AQBAT)." Institut national de santé publique du Québec.

Chan, A., Keoleian, G., and Gabler, E. (2008). "Evaluation of life-cycle cost analysis practices used by the Michigan department of transportation." Journal of Transportation Engineering, 134(6), 236-245.

Chatti, K., and Zaabar, I. (2012). "Estimating the Effects of Pavement Condition on Vehicle Operating Costs." Transportation Research Board, National Research Council, Washington, D.C., 87p.

Cucurachi, S., Heijungs, R., and Ohlau, K. (2012). "Towards a general framework for including noise impacts in LCA." Int J Life Cycle Ass, 17(4), 471-487.

Davies, H., and Kamp, I. (2012). Noise and cardiovascular disease: A review of the literature 2008-2011.

Environmental Protection Agency (2012). "Inventory of U.S. Greenhouse Gas Emissions and Sinks: 1990 -2010."

Feng, J., and Yang, W. (2012). "Effects of particulate air pollution on cardiovascular health: a population health risk assessment." PloS one, 7(3), e33385.

Gosse, C., Smith, B., and Clarens, A. (2013). "Environmentally Preferable Pavement Management Systems." Journal of Infrastructure Systems, 19(3), 315-325. 
Hanna, S. R., Briggs, G. A., and Hosker, R. P. J. (1982). Handbook on atmospheric diffusion, Technical Information Center, U.S. Deptartment of Energy.

Hendriks, R., Andrews, J., Buehler, D., Small, C., Job, J., and Durnan, J. (2009). "Technicla Noise Supplement." California Department of Transportation, 355.

Hurley, F., Hunt, A., Cowie, H., Holland, M., Miller, B., Pye, S., and Watkiss, P. (2005). "Methodology for the Cost-Benefit analysis for CAFE: Volume 2: Health Impact Assessment."

Journard, R., Andre, J. M., Rapone, M., Zallinger, M., Klijun, N., Andre, M., Samras, Z., Roujol, S., Laurikko, J., Weilenmann, M., Markewitz, K., Geivanidis, S., Ajtay, D., and Paturel, L. (2007). "Emission Factor Modelling and Database for Light Vehicles." Institut National de Recherche sur les Transports et leur Sécurité.

Kunzli, N., Kaiser, R., Medina, S., Studnicka, M., Chanel, O., Filliger, P., Herry, M., Horak, J. F., Puybonnieux-Texier, V., Quenel, P., Schneider, J., Seethaler, R., Vergnaud, J. C., and Sommer, H. (2000). "Public-health impact of outdoor and traffic-related air pollution: a European assessment." The Lancet, 356(9232), 795-801.

Lepeule, J., Laden, F., Dockery, D., and Schwartz, J. (2012). "Chronic Exposure to Fine Particles and Mortality: An Extended Follow-up of the Harvard Six Cities Study from 1974 to 2009." Environmental Health Perspectives, 120(7), 965-970.

Li, W. (2005). "A comparative study of the physical mechanisms related to source model of FHWA's traffic noise model (TNM): Measurements versus modeling assumptions." Ph.D. 3190028, University of Louisville, United States -- Kentucky.

Menge, C. W., Rossano, C. F., Anderson, G. S., and Bajdek, C. J. (1998). "FHWA Traffic Noise Model Technical Manual." Federal Highway Administration, 180.

Miedema, H. M. E., and Oudshoorn, C. G. M. (2001). "Annoyance from transportation noise: Relationships with exposure metrics DNL and DENL and their confidence intervals." Environmental Health Perspectives, 109(4), 409-416.

Molemaker, R.-J., Widerberg, O., and Kok, R. (2012). "Transport Emissions and Savings in Health Costs." World Bank.

Navrud, S., Trædal, Y., Hunt, A., Longo, A., Greßmann, A., Leon, C., Espino, R. E., Markovits-Somogyi, R., and Meszaros, F. (2006). "Economic values for key impacts valued in the Stated Preference surveys " HEATCO Developing Harmonised European Approaches for Transport Costing and Project Assessment European Commission.

Ostro, B. (1994). "Estimating Health Effects of Air Pollutants: A Methodology with an Application to Jakarta." The World Bank. 
Ozbay, K., Jawad, D., Parker, N., and Hussain, S. (2004). "Life-cycle cost analysis: state of the practice versus state of the art." Transportation Research Record: Journal of the Transportation Research Board, $1864,62-70$.

Pearce, D., Atkinson, G., and Mourato, S. (2006). Cost-benefit analysis and the environment: recent developments, OECD Publishing, Paris, France.

Pellecuer, L. (2014). "Modélisation des impacts environnementaux de la circulation routière en vue de leur intégration dans les systèmes de gestion des chaussées." Ph.D. thesis, École de Technologie Supérieure, Montréal, QC.

Pronello, C., and Camusso, C. (2012). "A Review of Transport Noise Indicators." Transport Reviews, 32(5), 599-628.

Rabl, A. (1999). "Air pollution and buildings: An estimation of damage costs in france." Environmental Impact Assessment Review, 19(4), 361-385.

Rabl, A., and Spadaro, J. V. (1999). "Damages and costs of air pollution: An analysis of uncertainties." Environment International, 25(1), 29-46.

SAAQ (2012). "Dossier statistique - Bilan 2011." Société de l'assurance automobile du Québec, Québec, QC.

Santero, N. J., and Horvath, A. (2009). "Global warming potential of pavements." Environmental Research Letters, 4(3).

Santero, N. J., Masanet, E., and Horvath, A. (2011). "Life-cycle assessment of pavements. Part I: Critical review." Resources, Conservation and Recycling, 55(9-10), 801-809.

Sawyer, D., Stiebert, S., and Welburn, C. (2007). "Evaluation of Total Cost of Air Pollution Due to Transportation in Canada."

Staatsen, B. A. M., Nijland, H., van Kempen, E., de Hollander, A. E. M., Franssen, A. E. M., and van Kamp, I. (2004). "Assessment of health impacts and policy options in relation to transport-related noise exposures Topic paper noise." Transport Related Health Effects with a Particular Focus on Children Towards an Integrated Assessment of their Costs and Benefits. State of the Art Knowledge, Methodological Aspects and Policy Directions.

Stieb, D., De Civita, P., Johnson, F. R., Manary, M., Anis, A., Beveridge, R., and Judek, S. (2002). "Economic evaluation of the benefits of reducing acute cardiorespiratory morbidity associated with air pollution." Environmental Health: A Global Access Science Source, 1(1), 7.

Tong, D., Mathur, R., Schere, K., Kang, D., and Yu, S. (2007). "The use of air quality forecasts to assess impacts of air pollution on crops: Methodology and case study." Atmospheric Environment, 41(38), 87728784. 
van Essen, H., Schroten, A., Otten, M., Sutter, D., Schreyer, C., Zandonella, R., Maibach, M., and Doll, C. (2011). "External Costs of Transport in Europe ".

Venkatram, A., and Horst, T. W. (2006). "Approximating dispersion from a finite line source." Atmospheric Environment, 40(13), 2401-2408.

Weisbrod, G., Lynch, T., and Meyer, M. (2009). "Extending monetary values to broader performance and impact measures: Transportation applications and lessons for other fields." Evaluation and Program Planning, 32(4), 332-341.

WHO (1999). "Guidelines for community noise." WHO, 160.

WHO (2011). "Burden of disease from environmental noise - Quantification of healthy life years lost in Europe." WHO Regional Office for Europe, Bonn.

Wordley, J., Walters, S., and Ayres, J. G. (1997). "Short term variations in hospital admissions and mortality and particulate air pollution." Occupational and environmental medicine, 54(2), 108-116.

World Health Organization (WHO) (2013). "Review of evidence on health aspects of air pollution REVIHAAP."

Zhang, H., Keoleian, G., and Lepech, M. (2013). "Network-Level Pavement Asset Management System Integrated with Life-Cycle Analysis and Life-Cycle Optimization." Journal of Infrastructure Systems, 19(1), 99-107.

Zhang, H., Lepech, M. D., Keoleian, G. A., Qian, S., and Li, V. C. (2010). "Dynamic life-cycle modeling of pavement overlay systems: Capturing the impacts of users, construction, and roadway deterioration." Journal of Infrastructure Systems, 16(4), 299-309. 


\section{Table 1. Limitations of PEIM}

\begin{tabular}{|c|c|c|c|}
\hline \multirow[t]{2}{*}{ Source } & \multirow[t]{2}{*}{ Limitation } & \multicolumn{2}{|c|}{ Impact } \\
\hline & & $\begin{array}{l}\text { Precision of the } \\
\text { outputs }\end{array}$ & $\begin{array}{c}\text { Minimization of } \\
\text { the total cost }\end{array}$ \\
\hline \multirow{3}{*}{$\begin{array}{l}\text { Lack of } \\
\text { knowledge }\end{array}$} & Not all types of pavement distresses considered & $\mathrm{x}$ & \\
\hline & Not all impacts considered & & $\mathrm{x}$ \\
\hline & Not all receptors considered & & $\mathrm{x}$ \\
\hline \multirow{9}{*}{ Hypothesis } & Road considered as a straight line & $\mathrm{x}$ & \\
\hline & Traffic considered continuous & $\mathrm{x}$ & \\
\hline & Engine and vehicle speed considered constant & $\mathrm{x}$ & \\
\hline & Roughness considered to represent pavement condition & $\mathrm{x}$ & \\
\hline & Pavement considered always dry & $\mathrm{x}$ & \\
\hline & $\begin{array}{l}\text { Exposure-response and exposure-cost functions considered to be the same in } \\
\text { North America and Europe }\end{array}$ & $\mathrm{x}$ & \\
\hline & Exposure to noise considered to cause early deaths and hospital admissions & $\mathrm{x}$ & \\
\hline & No noise barrier considered & $\mathrm{x}$ & \\
\hline & Unit costs considered to be the same in North America and Europe & $\mathrm{x}$ & \\
\hline
\end{tabular}


Table 2. Description of model parameters

\begin{tabular}{|c|c|c|c|c|}
\hline $\begin{array}{l}\text { Eq. } \\
\text { No. }\end{array}$ & Parameter & Unit & Description & Value \\
\hline \multirow[t]{5}{*}{1} & FCLIM & & $\begin{array}{l}\text { Climatic factor related to the percentage of driving on } \\
\text { snow or wet surface }\end{array}$ & $\begin{array}{l}\text { Assuming the road is always } \\
\text { dry, the value is set to } 1 \\
\text { (Bennett and Greenwood 2001) }\end{array}$ \\
\hline & $b 11_{i}$ to $b 13_{i}$ & & Rolling resistance parameters for vehicle class i & see Table 3 \\
\hline & $N w_{i}$ & & Vehicle number of wheels for vehicle class i & see Table 3 \\
\hline & $C R 1_{i}$ & & Rolling resistance tire factor for vehicle class i & see Table 3 \\
\hline & $M_{i}$ & tons & Mass for vehicle class i & see Table 3 \\
\hline \multirow[t]{2}{*}{2} & $\operatorname{Kcr} 2_{i}$ & & Calibration factor for vehicle class i & see Table 3 \\
\hline & $a 0_{i}$ to $a 3_{i}$ & & $\begin{array}{l}\text { Parameters for rolling resistance coefficient for vehicle } \\
\text { class i }\end{array}$ & see Table 3 \\
\hline 3 & $\alpha_{\mathrm{i}}$ & $\mathrm{mL} / \mathrm{s}$ & Fuel consumption at idling for vehicle class $\mathrm{i}$ & see Table 3 \\
\hline 4 & $C P F_{i, j}$ & & $\begin{array}{l}\text { Catalyst pass fraction of emission } \mathrm{j} \text { from vehicles of } \\
\text { class } \mathrm{i}\end{array}$ & see Table 4 \\
\hline 5 & $a_{i}$ & & $\begin{array}{l}\text { Proportion of vehicle class } i \text { in the annual average } \\
\text { daily traffic }\end{array}$ & see Table 5 \\
\hline \multirow[t]{2}{*}{8} & $C R F_{j, h}$ & $\mu \mathrm{g}^{-1} \cdot \mathrm{m}^{3}$ & $\begin{array}{l}\text { Concentration-response function for health outcome } h \\
\text { associated with an increase by one unit of the } \\
\text { concentration of emission } \mathrm{j}\end{array}$ & see Table 6 \\
\hline & $N_{h}$ & & $\begin{array}{l}\text { Base number of cases for the health outcome } h \text { per } \\
\text { person and per year }\end{array}$ & see Table 7 \\
\hline \multirow[t]{4}{*}{10} & $U V_{h}$ & $\mathrm{CA} \$_{2000} /$ case & Economic value for one case of health outcome $h$ & see Table 8 \\
\hline & $U V_{\mathrm{CO}_{2}}$ equ & $\mathrm{CA} \$_{2000} / \mathrm{g}$ & Economic value for an additional gram of $\mathrm{CO}_{2}$ & $\begin{array}{l}\text { Assuming an average climate } \\
\text { sensitivity and a } 1.5 \% \text { discount } \\
\text { rate for damage valuation, low, } \\
\text { central, and high estimates are } \\
\text { set to } 202.99,484.24 \text {, and } \\
765.50 \text {, respectively (adjusted } \\
\text { from Ackerman and Stanton } \\
2012 \text { ). }\end{array}$ \\
\hline & $U V B L_{j}$ & $\mathrm{CA} \$_{2000} /$ ton & $\begin{array}{l}\text { Economic value of biodiversity loss because of change } \\
\text { in the concentration of emission } j \text { per ton of emission } j\end{array}$ & see Table 9 \\
\hline & $U V B D_{P M}$ & $\mathrm{CA} \$_{2000} /$ ton & $\begin{array}{l}\text { Economic value of building damage because of change } \\
\text { in the concentration of particulate matter (PM) per ton } \\
\text { of PM }\end{array}$ & $\begin{array}{l}275.77 \text { (central value only, } \\
\text { adjusted from Rabl 1999) }\end{array}$ \\
\hline \multirow[t]{2}{*}{13} & $\Delta L_{A}$ & dBA/year & Age component of noise level increase & 0.4 (Bendtsen et al. 2009) \\
\hline & $\Delta L_{C T V}$ & $\mathrm{dBA} / 10^{6}$ veh & Traffic component of noise level increase & 0.21 (Bendtsen et al. 2009) \\
\hline 14 & $b_{k}$ & & $\begin{array}{l}\text { The proportion of the annual average daily traffic for } \\
\text { the } \mathrm{k}^{\text {th }} \text { hour of the day }\end{array}$ & see Table 10 \\
\hline 16 & $\propto$ & & Ground absorption parameter & $\begin{array}{l}\text { Assuming the ground is } \\
\text { reflective, the value is set to } 1 \\
\text { (Hendriks et al. 2009) }\end{array}$ \\
\hline 17 & $P_{\text {den }_{k}}$ & & $\begin{array}{l}\text { Penalty coefficient for the } \mathrm{k}^{\text {th }} \text { hour of the day for } L_{d e n_{s}} \\
\text { noise level calculation }\end{array}$ & $\begin{array}{l}10 \text { for } \mathrm{k}=1 \ldots 6 \text { and } \mathrm{k}=23 \ldots 24 \text {, } \\
\text { and } 5 \text { for } \mathrm{k}=19 \ldots 22 \text { (Pronello } \\
\text { and Camusso 2012) }\end{array}$ \\
\hline 18 & $a_{h}$ and $b_{h}$ & & $\begin{array}{l}\text { Parameters for calculation of the number of cases for } \\
\text { each health outcomes h occurring along road section s }\end{array}$ & see Table 11 \\
\hline 19 & $\begin{array}{l}a_{X A}, b_{X A}, c_{X A} \\
\text { and } L_{X A}\end{array}$ & & $\begin{array}{l}\text { Parameters for calculation of percentage of people that } \\
\text { is annoyed by noise level }\end{array}$ & see Table 12 \\
\hline \multirow[t]{2}{*}{20} & $U V_{h}$ & $\mathrm{CA} \$_{2000} /$ case & Economic value for one case of health outcome $\mathrm{h}$ & see Table 11 \\
\hline & $U V A_{X A}$ & $\mathrm{CA} \$_{2000} /$ year & $\begin{array}{l}\text { Economic value for one person alternatively lightly } \\
\text { annoyed, annoyed, and highly annoyed per year }\end{array}$ & see Table 12 \\
\hline
\end{tabular}


Table 3. Model parameters for fuel consumption

\begin{tabular}{lccccccccccccc}
\hline Vehicle class & b11 & $\mathrm{b} 12$ & $\mathrm{~b} 13$ & $\mathrm{Nw}$ & $\mathrm{CR} 1$ & $\mathrm{M}$ & $\mathrm{Kcr} 2$ & $\mathrm{a} 0$ & $\mathrm{a} 1$ & $\mathrm{a} 2$ & $\mathrm{a} 3$ & $\alpha$ \\
\hline Motorcycle & 20.35 & 0.11636 & 0.07934 & 2 & 1.3 & 0.20 & 1.00 & 0.50 & 0.02 & 0.10 & 0 & 0.12 \\
Small car & 22.94 & 0.10323 & 0.12487 & 4 & 1.0 & 1.90 & 0.50 & 0.50 & 0.02 & 0.10 & 0 & 0.65 \\
Medium car & 22.94 & 0.10323 & 0.12487 & 4 & 1.0 & 1.90 & 0.50 & 0.50 & 0.02 & 0.10 & 0 & 0.65 \\
Large car & 22.94 & 0.10323 & 0.12487 & 4 & 1.0 & 1.90 & 0.50 & 0.50 & 0.02 & 0.10 & 0 & 0.65 \\
Light delivery car & 25.90 & 0.09143 & 0.09796 & 4 & 1.0 & 2.54 & 0.67 & 0.57 & 0.04 & 0.04 & 1.34 & 0.65 \\
Light good vehicle & 25.90 & 0.09143 & 0.09796 & 4 & 1.0 & 2.54 & 0.67 & 0.57 & 0.04 & 0.04 & 1.34 & 0.65 \\
Four-wheel drive & 25.90 & 0.09143 & 0.09796 & 4 & 1.0 & 2.50 & 0.58 & 0.50 & 0.02 & 0.10 & 0 & 0.65 \\
Light truck & 29.60 & 0.08000 & 0.07500 & 4 & 1.0 & 4.50 & 0.99 & 0.57 & 0.04 & 0.04 & 1.34 & 0.70 \\
Medium truck & 29.60 & 0.08000 & 0.11250 & 6 & 1.3 & 6.50 & 0.99 & 0.57 & 0.04 & 0.04 & 1.34 & 0.80 \\
Heavy truck & 38.85 & 0.06095 & 0.10884 & 10 & 1.3 & 13.00 & 1.10 & 0.57 & 0.04 & 0.04 & 1.34 & 0.90 \\
Articulated truck & 38.85 & 0.06095 & 0.19592 & 18 & 1.3 & 13.6 & 1.10 & 0.57 & 0.04 & 0.04 & 1.34 & 0.90 \\
Mini bus & 25.90 & 0.09143 & 0.09796 & 4 & 1.0 & 2.16 & 0.67 & 0.50 & 0.02 & 0.10 & 0 & 0.48 \\
Light bus & 29.60 & 0.08000 & 0.07500 & 4 & 1.0 & 2.50 & 0.99 & 0.50 & 0.02 & 0.10 & 0 & 0.48 \\
Medium bus & 38.85 & 0.06095 & 0.06531 & 6 & 1.3 & 4.50 & 0.99 & 0.57 & 0.04 & 0.04 & 1.34 & 0.70 \\
Heavy bus & 38.85 & 0.06095 & 0.10884 & 10 & 1.3 & 13.00 & 1.10 & 0.57 & 0.04 & 0.04 & 1.34 & 0.80 \\
Coach & 38.85 & 0.06095 & 0.10884 & 10 & 1.3 & 13.60 & 1.10 & 0.57 & 0.04 & 0.04 & 1.34 & 0.90 \\
\hline Note: values for motorcycle are taken from Bennett and Greenwood (2001); all other values are taken from Chatti and Zaabar \\
(2012).
\end{tabular}


Table 4. Model parameters for atmospheric emission

\begin{tabular}{|c|c|c|c|c|c|c|}
\hline Vehicle class & $C P F_{H C}$ & $C P F_{C O}$ & $C P F_{N O_{X}}$ & $\mathrm{CPF}_{\mathrm{SO}_{2}}$ & $C P F_{P b}$ & $C P F_{P M}$ \\
\hline Motorcycle & 1.00000 & 1.00000 & 1.00000 & 1.00000 & 1.00000 & 1.00000 \\
\hline Small car & 0.86454 & 0.86454 & 0.83311 & 1.00000 & 1.00000 & 1.00000 \\
\hline Medium car & 0.85639 & 0.85639 & 0.82666 & 1.00000 & 1.00000 & 1.00000 \\
\hline Large car & 0.85639 & 0.85639 & 0.82666 & 1.00000 & 1.00000 & 1.00000 \\
\hline Light delivery car & 0.89675 & 0.89675 & 0.86369 & 1.00000 & 1.00000 & 1.00000 \\
\hline Light good vehicle & 0.89675 & 0.89675 & 0.86369 & 1.00000 & 1.00000 & 1.00000 \\
\hline Four-wheel drive & 0.93113 & 0.93113 & 0.87169 & 1.00000 & 1.00000 & 0.86641 \\
\hline Light truck & 1.02273 & 1.02273 & 0.92301 & 1.00000 & 1.00000 & 0.96094 \\
\hline Medium truck & 1.03200 & 1.03200 & 0.93544 & 1.00000 & 1.00000 & 0.97750 \\
\hline Heavy truck & 1.04426 & 1.04426 & 0.97778 & 1.00000 & 1.00000 & 1.01536 \\
\hline Articulated truck & 1.04483 & 1.04483 & 0.98937 & 1.00000 & 1.00000 & 1.02072 \\
\hline Mini bus & 0.96722 & 0.96722 & 0.93339 & 1.00000 & 1.00000 & 1.00000 \\
\hline Light bus & 0.96880 & 0.96880 & 0.88656 & 1.00000 & 1.00000 & 0.89813 \\
\hline Medium bus & 1.02677 & 1.02677 & 0.92786 & 1.00000 & 1.00000 & 0.96769 \\
\hline Heavy bus & 1.04294 & 1.04294 & 0.96631 & 1.00000 & 1.00000 & 1.00793 \\
\hline Coach & 1.04306 & 1.04306 & 0.96704 & 1.00000 & 1.00000 & 1.00847 \\
\hline
\end{tabular}

Note: values for motorcycle are taken from Bennett and Greenwood (2001); all other values are taken from Chatti and Zaabar (2012). 
Table 5. Percentage of vehicle classes in the annual average daily traffic (data from Société de l'assurance automobile du Québec (SAAQ 2012))

\begin{tabular}{ll}
\hline Vehicle class & \multicolumn{1}{c}{$\boldsymbol{a}$} \\
\hline Motorcycle & 3,572 \\
Small car & 10,949 \\
Medium car & 38,324 \\
Large car & 5,539 \\
Light delivery car & 11,016 \\
Light good vehicle & 15,775 \\
Four-wheel drive & 7,403 \\
Light truck & 6,835 \\
Medium truck & 0,178 \\
Heavy truck & 0,227 \\
Articulated truck & 0,063 \\
Mini bus & 0,03 \\
Light bus & 0,04 \\
Medium bus & 0,043 \\
Heavy bus & 0,002 \\
Coach & 0,002 \\
\hline
\end{tabular}


Table 6. Model parameters for concentration-response function

\begin{tabular}{|c|c|c|c|c|c|c|}
\hline \multirow[t]{2}{*}{ Health outcome } & \multicolumn{3}{|c|}{$C R F_{P M_{2.5}}$} & \multicolumn{3}{|c|}{$C R F_{\boldsymbol{P M}}$} \\
\hline & Low & Central & High & Low & Central & High \\
\hline Mortality & 0.06542 & 0.12281 & 0.18033 & 0.00044 & 0.04123 & 0.05749 \\
\hline Respiratory hospital admission & - & - & - & 0.00100 & 0.04287 & 0.06280 \\
\hline Cardiac hospital admission & 0.18699 & 0.24242 & 0.30070 & 0 & 0.13043 & 0.18033 \\
\hline Respiratory emergency visit & - & - & - & 0.00100 & 0.04287 & 0.06280 \\
\hline Cardiac emergency visit & 0.18699 & 0.24242 & 0.30070 & 0.06542 & 0.13043 & 0.18033 \\
\hline Restricted activity day & 0,79200 & 0.90200 & 1.01300 & 0.04000 & 0.06000 & 0.09000 \\
\hline Asthma symptom day (total) per asthmatic & - & - & - & 0.02000 & 0.03000 & 0.27000 \\
\hline Acute respiratory symptom day & - & - & - & 0.00002 & 0.18300 & 0.27400 \\
\hline Bronchitis case (adult) & - & - & - & 3.06000 & 6.12000 & 9.18000 \\
\hline Bronchitis case (child) & - & - & - & 0.00002 & 0.00169 & 0.00238 \\
\hline
\end{tabular}

Note: - denotes no available data; values are taken from Feng and Yang (2012); Kunzli et al. (2000); Lepeule et al. (2012); Molemaker et al. (2012); Ostro (1994); Wordley et al. (1997); low estimates are the lowest of the low estimates among the available data; central estimates are the highest estimates of the central estimates among the available data; high estimates are the highest of the high estimates among the available data. 
Table 7. Model parameters for health outcome quantification (data from Bouchard and Smargiassi (2008))

\begin{tabular}{lc}
\hline Health outcome & $N$ \\
\hline Mortality & 0.01034 \\
Respiratory hospital admission & 0.00164 \\
Cardiac hospital admission & 0.02282 \\
Respiratory emergency visit & 0.00822 \\
Cardiac emergency visit & 0.03003 \\
Restricted activity day & 1 \\
Asthma symptom day (total) per asthmatic & 60 \\
Acute respiratory symptom day & 1 \\
Bronchitis case (adult) & 1 \\
Bronchitis case (child) & 1 \\
\hline
\end{tabular}


Table 8. Model parameters for health outcome valuation

\begin{tabular}{|c|c|c|c|}
\hline \multirow[t]{2}{*}{ Health outcome } & \multicolumn{3}{|c|}{$U V$} \\
\hline & Low & Central & High \\
\hline Mortality & 5949471.81 & 12394732.93 & 16361047.47 \\
\hline Respiratory hospital admission & 2740.80 & 3893.57 & 4635.21 \\
\hline Cardiac hospital admission & 2740.80 & 4820.62 & 5933.06 \\
\hline Respiratory emergency visit & 918.17 & 2970.40 & 3282.30 \\
\hline Cardiac emergency visit & 3059.24 & 4078.98 & 5191.43 \\
\hline Restricted activity day & 12.051 & 249.03 & 312.19 \\
\hline Asthma symptom day (total) per asthmatic & 10.20 & 88.42 & 178.22 \\
\hline Acute respiratory symptom day & 10.40 & 72.18 & 90.23 \\
\hline Bronchitis case (adult) & 180698.14 & 395063.84 & 690619.12 \\
\hline Bronchitis case (child) & 222.78 & 460.41 & 683.19 \\
\hline
\end{tabular}


Table 9. Model parameters for biodiversity loss valuation (data from van Essen et al. 2011)

\begin{tabular}{lccc}
\hline Emission & \multicolumn{3}{c}{ UVBL } \\
\cline { 2 - 4 } & Low & Central & High \\
\hline $\mathrm{NO}_{\mathrm{x}}$ & 299.04 & 1121.38 & 2242.76 \\
$\mathrm{SO}_{2}$ & 74.76 & 224.28 & 448.55 \\
\hline
\end{tabular}


Table 10. Model parameters for daily traffic distribution (Quebec Ministry of Transportation (MTQ), unpublished data, 2013)

\begin{tabular}{lc}
\hline Hour & Percentage of daily traffic \\
\hline $0-1$ & 1.00 \\
$1-2$ & 0.50 \\
$2-3$ & 0.50 \\
$3-4$ & 0.50 \\
$4-5$ & 0.50 \\
$5-6$ & 1.00 \\
$6-7$ & 3.50 \\
$7-8$ & 7.50 \\
$8-9$ & 9.00 \\
$9-10$ & 5.50 \\
$10-11$ & 5.00 \\
$11-12$ & 5.50 \\
$12-13$ & 5.50 \\
$13-14$ & 5.50 \\
$14-15$ & 6.50 \\
$15-16$ & 8.00 \\
$16-17$ & 9.00 \\
$17-18$ & 6.50 \\
$18-19$ & 5.00 \\
$19-20$ & 4.00 \\
$20-21$ & 3.00 \\
$21-22$ & 2.75 \\
$22-23$ & 2.75 \\
$23-24$ & 1.50 \\
\hline & \\
\hline &
\end{tabular}


Table 11. Model parameters for health outcome quantification and valuation

\begin{tabular}{|c|c|c|c|c|c|c|}
\hline \multicolumn{2}{|c|}{ Health outcome (per 1000 adults exposed) } & \multirow[t]{2}{*}{$a$} & \multirow[t]{2}{*}{$\boldsymbol{b}$} & \multicolumn{3}{|c|}{$U V$} \\
\hline & & & & Low & Central & High \\
\hline \multirow[t]{2}{*}{ Myocardial infarction } & years of life lost & 0.084 & 5.25 & 2269867.46 & 2299960.40 & 2424631.15 \\
\hline & days in hospital & 0.504 & 31.5 & 37525.78 & 44682.76 & 47390.80 \\
\hline Angina pectoris & days in hospital & 0.168 & 10.5 & 19142.26 & 22939.07 & 24204.67 \\
\hline Hypertension & days in hospital & 0.063 & 4.5 & 1902.31 & 2228.42 & 2391.47 \\
\hline Sleep disturbance & cases & 0.62 & 43.2 & 975.54 & 975.54 & 1024.32 \\
\hline
\end{tabular}

Note: $a$ and $b$ values are taken from Staatsen et al. (2004); $U V$ values are adjusted from Bickel et al. (2006). 
Table 12. Model parameters for annoyance quantification and valuation

\begin{tabular}{lccccc}
\hline Annoyance level & $\boldsymbol{a}$ & $\boldsymbol{b}$ & $\boldsymbol{c}$ & $\boldsymbol{L}$ & $\boldsymbol{U V}$ \\
\hline Little annoyed & -0.0006235 & 0.05509 & 0.6693 & 32 & 56.59 \\
Annoyed & 0.0001795 & 0.02110 & 0.5353 & 37 & 130.013 \\
Highly annoyed & 0.0009868 & -0.01436 & 0.5118 & 42 & 130.013 \\
\hline
\end{tabular}

Note: $a, b, c$, and $L$ values are taken from Miedema and Oudshoorn (2001); UV values are adjusted from Navrud et al. (2006). 
Table 13. Pavement age and corresponding pavement roughness

\begin{tabular}{|l|l|}
\hline Pavement age (year) & Pavement roughness (m/km) \\
\hline 0 & 1.00 \\
\hline 5 & 1.75 \\
\hline 10 & 2.50 \\
\hline 15 & 3.25 \\
\hline 20 & 4.00 \\
\hline
\end{tabular}


Inputs

Outputs

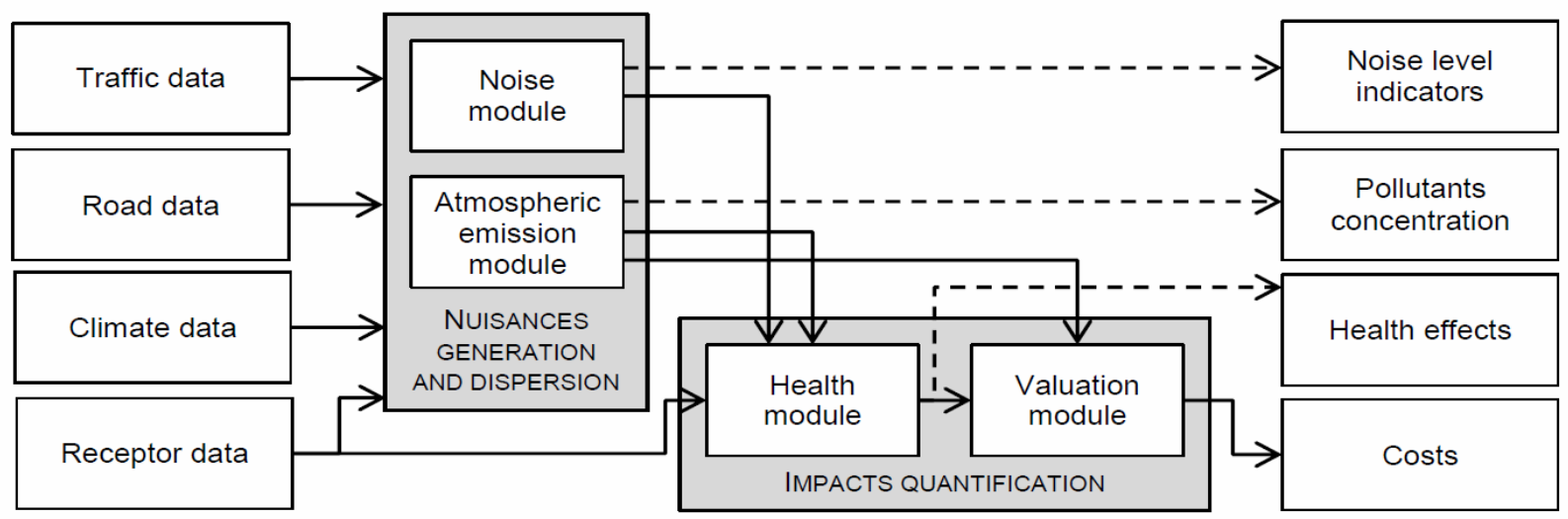

Fig. 1. Schematic architecture of PEIM with arrows representing the links between inputs, modules, and outputs (dashed arrows emphasize the link between modules and intermediate outputs) 

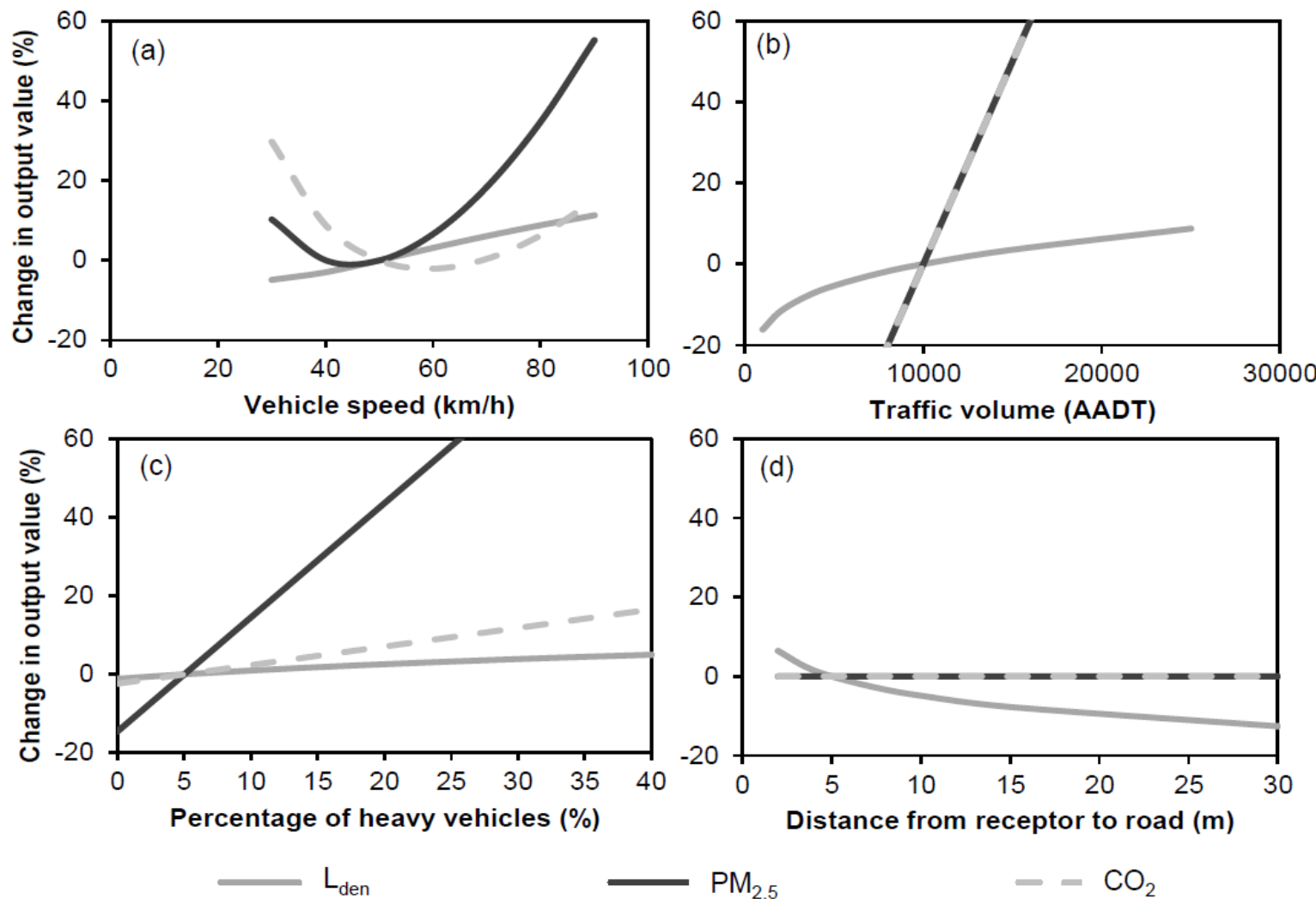

$\mathrm{PM}_{2.5}$

$--\mathrm{CO}_{2}$

Fig. 2. Sensitivity of $\mathrm{L}_{\mathrm{den}}$ and emissions of $\mathrm{CO}_{2}$ and $\mathrm{PM}_{2.5}$ to (a) vehicle speed, (b) traffic volume, (c) percentage of heavy vehicles, and (d) distance from receptor to road 

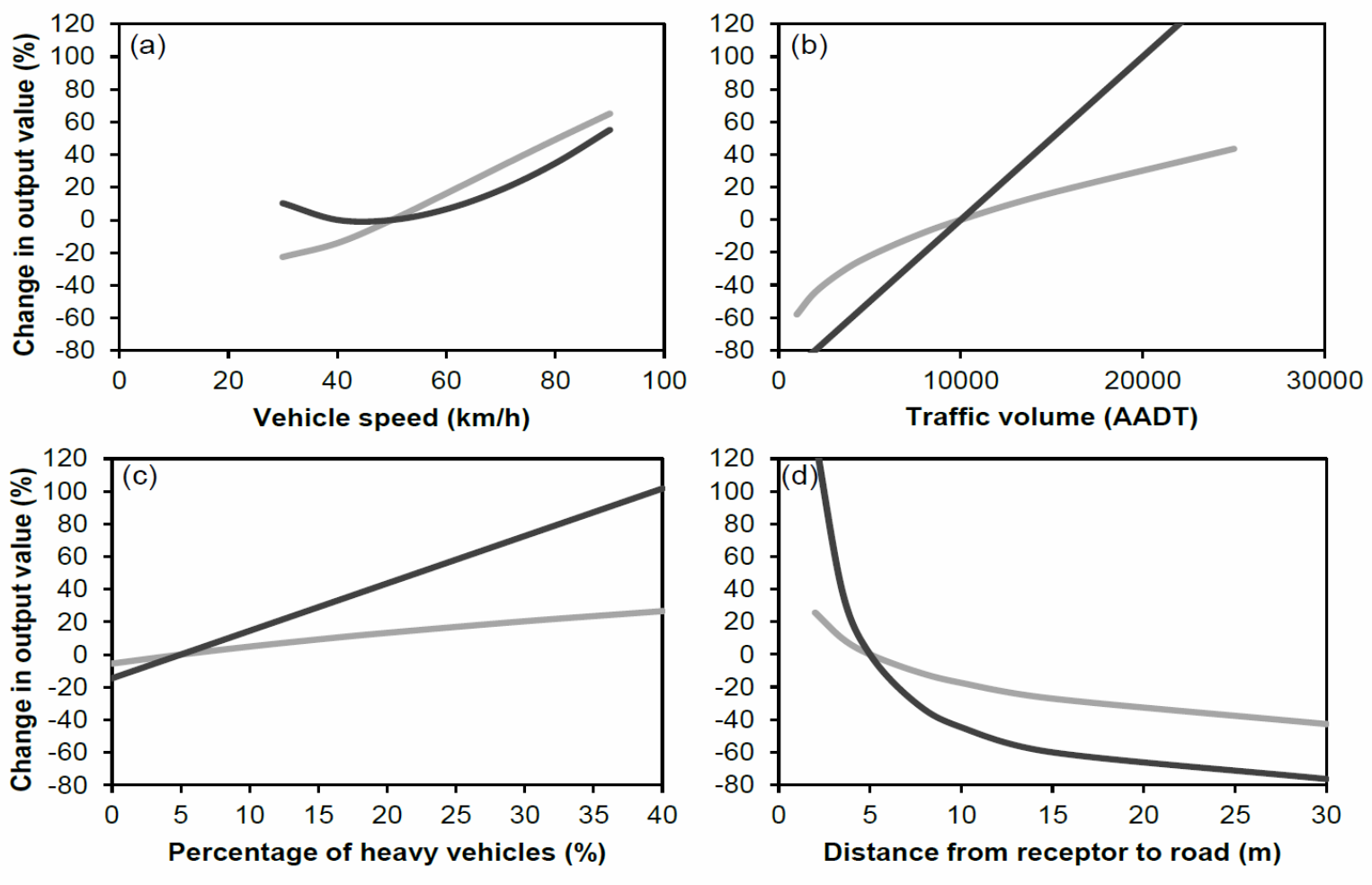

Noise annoyance

- Hospital admissions due to air pollution

Fig. 3. Sensitivity of noise annoyance and hospital admissions due to (a) air pollution to vehicle speed, (b) traffic volume, (c) percentage of heavy vehicles, and (d) distance from receptor to road 
(a)

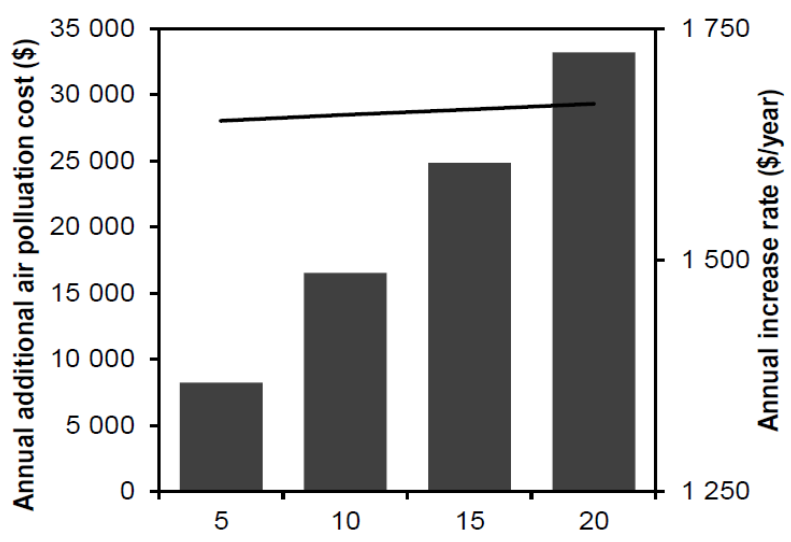

(b)

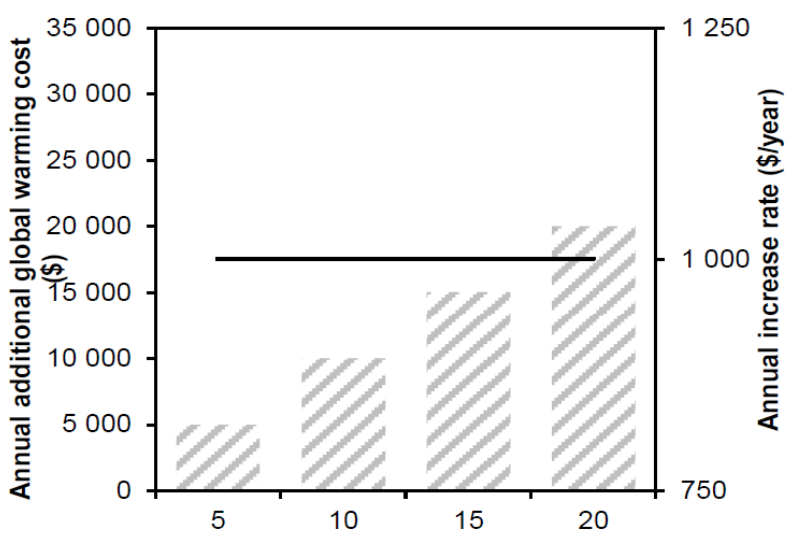

(c)

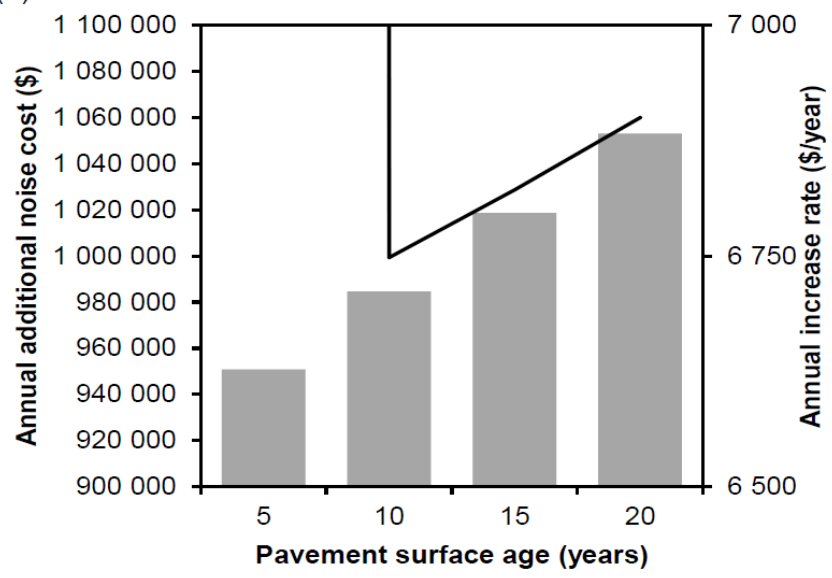

Fig. 4. Annual additional costs and annual rate of increase in cost related to air pollution (a), global warming (b), and noise impacts (c); * indicates an annual rate of increase value of 190,000 Canadian dollars per year 


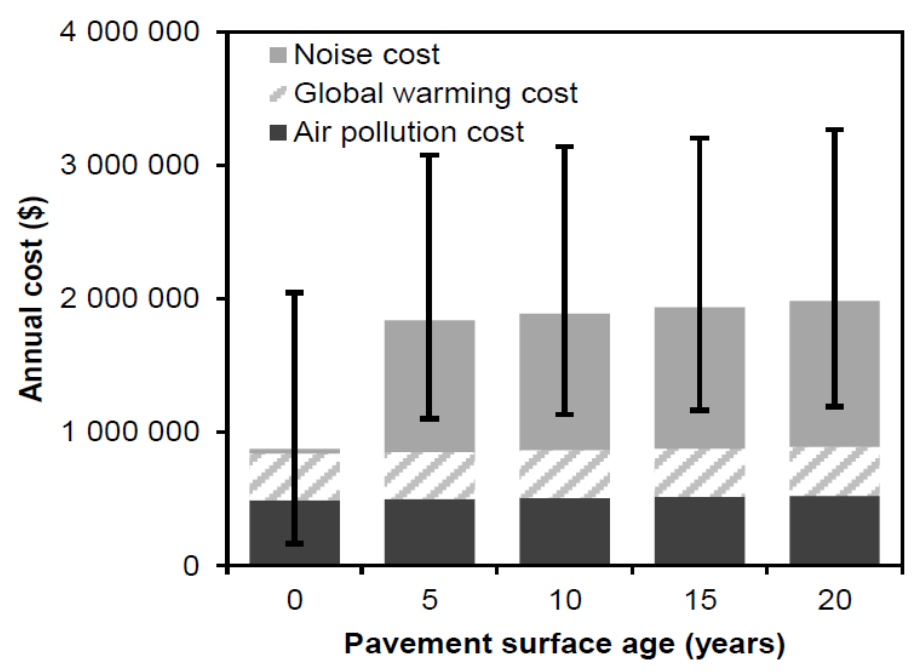

